\title{
On the Bennelongia nimala and B. triangulata lineages (Crustacea, Ostracoda) in Western Australia, with the description of six new species
}

\author{
Koen MARTENS ${ }^{1,2,5}$, Stuart HALSE ${ }^{3,6} \&$ Isa SCHÖN ${ }^{1,4,7}$ \\ ${ }^{1}$ Royal Belgian Institute of Natural Sciences, Operational Directorate "Natural Environment", \\ Freshwater Biology, Vautierstraat 29, B-1000 Brussels, Belgium. \\ Corresponding author: darwinula@gmail.com \\ ${ }^{2}$ University of Ghent, Department of Biology, K.L. Ledeganckstraat 35, B-9000 Gent, Belgium. \\ ${ }^{3}$ Bennelongia Environmental Consultants, 5 Bishop Street, Jolimont WA 6014, Australia. \\ ${ }^{4}$ University of Hasselt, Research Group Zoology, Agoralaan Building D, \\ B-3590 Diepenbeek, Belgium. \\ ${ }^{5}$ urn:1sid:zoobank.org:author:9272757B-A9E5-4C94-B28D-F5EFF32AADC7 \\ ${ }^{6}$ urn:lsid:zoobank.org:author:676014BF-5979-49EC-BC8F-811214170111 \\ ${ }^{7}$ urn:1sid:zoobank.org:author:94232F10-7092-4E90-9071-64C4FDABE691
}

\begin{abstract}
The ostracod genus Bennelongia De Deckker \& McKenzie, 1981 occurs in Australia and New Zealand. We redescribe $B$. nimala from the Northern Territory and describe six new species from Western Australia belonging to the $B$. nimala (five species) and $B$. triangulata sp. nov. (one species) lineages: B. tirigie sp. nov., B. koendersae sp. nov., B. pinderi sp. nov., B. muggon sp. nov., B. shieli sp. nov. and $B$. triangulata sp. nov. For six of these seven species, we could construct molecular phylogenies and parsimonious networks based on COI sequences. We tested for specific status and for potential cryptic diversity of clades with Birky's 4 theta rule. The analyses support the existence of these six species and the absence of cryptic species in these lineages. Bennelongia triangulata sp. nov. is a common species in the turbid claypans of the Murchison/ Gascoyne region. Bennelongia nimala itself is thus far known only from the Northern Territory. Bennelongia tirigie sp. nov., B. pinderi sp. nov. and B. muggon sp. nov. occur in the Murchison/ Gascoyne region, whereas B. koendersae sp. nov. and B. shieli sp. nov. are described from the Pilbara. With the six new species described here, the genus Bennelongia now comprises 31 nominal species.
\end{abstract}

Keywords. Taxonomy, evolution, biodiversity, Western Australia, Pilbara

Martens K., Halse S. \& Schön I. 2015. On the Bennelongia nimala and B. triangulata lineages (Crustacea, Ostracoda) in Western Australia, with the description of six new species. European Journal of Taxonomy 111: 1-36. http://dx.doi.org/10.5852/ejt.2015.111

\section{Introduction}

The genus Bennelongia was originally described by De Deckker \& McKenzie (1981) from Queensland, with Bennelongia harpago as type species. Subsequently, De Deckker (1981) redescribed and transferred Chlamydotheca australis Brady, 1886 to Bennelongia and added a further three species to the genus: 
Bennelongia barangaroo De Deckker, 1981, Bennelongia nimala De Deckker, 1981 and Bennelongia pinpi De Deckker, 1981. De Deckker (1982) then described Bennelongia tunta De Deckker, 1982 from Queensland. For about 30 years after those papers, nothing was added to the taxonomy of the genus Bennelongia, but Halse (2002) highlighted its high frequency of occurrence in Western Australia (WA). Then Martens et al. $(2012,2013)$ and Shearn et al. (2012) together added 19 new species, mostly from WA. De Deckker \& Martens (2013) illustrated how different the valve morphologies of adult and juvenile Bennelongia species can be and how juvenile morphologies vary between the lineages within the genus.

Here, we redescribe Bennelongia nimala from the Northern Territory (NT) and describe six new species in the B. nimala and Bennelongia triangulata lineages within the genus, thus bringing the total number of species in the genus to 31 (see Discussion). This is the fifth contribution in the recent revision of the genus Bennelongia.

\section{Material and methods}

\section{Collections}

Ostracods were collected from pans and lakes with a hand net of mesh size of $250 \mu \mathrm{m}$ during several field trips (see below) (Fig. 1). Material for morphological analyses originated from both these 'new' collections and from earlier samples from all over WA, mostly collected by the research group of one of us ( $\mathrm{SH})$ and preserved in a collection housed at the Department of Parks and Wildlife, Perth. The molecular analyses were successful only with newly collected material, using either living specimens or specimens sorted directly in the field and preserved in $100 \%$ ethanol. Consequently, molecular analyses were limited to six of the seven species (re-)described here. Locations of populations used for the present paper are indicated on the map in Fig. 1. Type material of the new species is deposited in the Western Australian Museum, Perth, Australia (WAMC numbers) and in the Ostracod Collection of the Royal Belgian Institute of Natural Sciences, Brussels, Belgium (OC numbers) (see Table 1).

\section{Morphological analyses}

Ostracods were dissected with valves stored dry in micropalaeontological slides and soft parts in glycerine in sealed slides, or with soft parts used for molecular analyses. Drawings of soft parts were made with a camera lucida on a compound microscope (Leica, DM 2500 at Bennelongia Environmental Consultants, Perth). Valves were illustrated and measured using scanning electron microscopy (Philips XL30 SEM at the Royal Belgian Institute of Natural Sciences, Brussels).

\section{Molecular analysis}

We used the Qiagen Blood and Tissue extraction kit following the manufacturer's protocol to extract DNA from 54 ostracods representing six species of the Bennelongia nimala and B. triangulata lineages. The universal PCR primers of Folmer et al. (1994) for amplifying part of the mitochondrial COI region were applied with the following conditions: $25 \mu \mathrm{l}$ volumes of the HotStar Master Mix (Qiagen; $1.5 \mathrm{mM}$ $\mathrm{MgCl}_{2}, 200 \mu \mathrm{M}$ dNTP, Tris $\cdot \mathrm{Cl}, \mathrm{KCl},\left(\mathrm{NH}_{4}\right)_{2} \mathrm{SO}_{4}, 1.25 \mathrm{U}$ Taq) and $0.1 \mu \mathrm{M}$ of each primer were applied. In a T personal Thermoblock (Biometra), we conducted PCRs with 15 min at $95^{\circ} \mathrm{C}, 40$ cycles with $1 \mathrm{~min}$ at $95^{\circ} \mathrm{C}, 1 \mathrm{~min}$ at $44^{\circ} \mathrm{C}, 1 \mathrm{~min}$ at $72^{\circ} \mathrm{C}$, followed by a final extension step for $10 \mathrm{~min}$ at $72^{\circ} \mathrm{C}$. Success of PCR amplifications was verified by agarose gel electrophoresis and staining of gels with Gelred ${ }^{\mathrm{TM}}$. We cleaned PCR products with the GFX ${ }^{\mathrm{TM}}$ PCR DNA and gel band purification kit (GE Healthcare) and sequenced them in both directions with the universal primers and the Big Dye kit (ABI) on an ABI 3130X following the manufacturer's protocol.

No fresh (living) material of $B$. shieli sp. nov. was obtained and this species is not represented in the molecular phylogenetic tree and networks. 


\section{Analyses of sequence data}

We used BioEdit (Hall 2007) to visualize sequence chromatograms. Sequence editing included alignments of the forward and reverse sequence of each individual with ClustalX (Larkin et al. 2007), followed by manual checking and correcting of ambiguities and trimming the final alignment to equal length. We confirmed identity of the obtained sequences by BLAST searches (Altschul et al. 1990) in Genbank. The optimal model of molecular COI evolution was assessed with 88 or 24 models and the AICc criterion in jModeltest 2.1.1 (Darriba et al. 2012). We reconstructed phylogenies with two different methods, Bayesian Inference (BI) in Mr Bayes 3.2 (Ronquist et al. 2011; with 5 million generations, sampling every $100^{\text {th }}$ generation, a burn-in of $25 \%$ and the parameters identified by jModeltest for 24 different models) and the Maximum-Likelihood method in PhyML (Guindon \& Gascuel 2003; with 1000

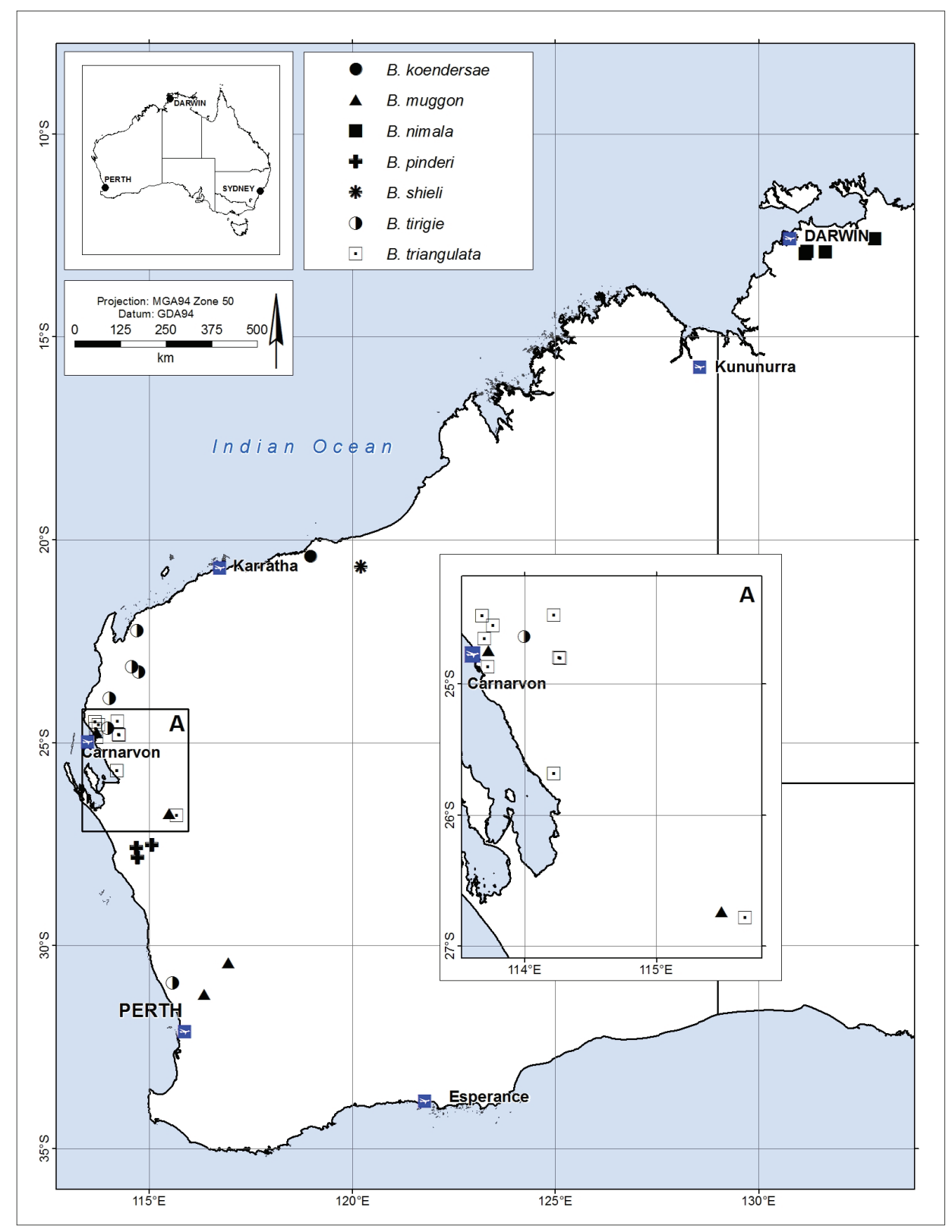

Fig. 1. Map of Western Australia with localities of Bennelongia species described in the present paper. 
Table 1. Individual measurements of specimens used for the present descriptions. All measurements were done using SEM (see Material and methods). If a molecular sequence was available for the same specimen, the GenBank registration number is also given. However, some specimens were used as whole animals for DNA sequencing, and thus no measurements are available. The present table therefore does not list all 54 specimens for which sequences are available. Specimens in bold are holotypes. Abbreviations: see Material and methods.

\begin{tabular}{|c|c|c|c|c|c|c|c|c|c|c|c|c|c|}
\hline \multirow{2}{*}{ Museum nr } & \multirow{2}{*}{ KMWA/OS } & \multirow{2}{*}{ Genbank } & \multirow{2}{*}{$\begin{array}{c}\text { Bennelongia } \\
\text { species }\end{array}$} & \multirow{2}{*}{ Locality } & \multirow{2}{*}{ ôto } & \multicolumn{2}{|c|}{$\mathbf{R V}$} & \multicolumn{2}{|c|}{ LV } & \multicolumn{2}{|c|}{ CpRL } & \multicolumn{2}{|c|}{$\mathrm{CPD} / \mathrm{V}$} \\
\hline & & & & & & $\mathbf{L}$ & H & $\mathbf{L}$ & H & $\mathbf{L}$ & H & $\mathbf{L}$ & $\mathbf{W}$ \\
\hline WAMC55564 & KMWA.1361 & & triangulata & SIKE07 & $\sigma^{\lambda}$ & 1850 & 1158 & 1923 & 1188 & & & & \\
\hline WAMC55565 & KMWA.885 & & triangulata & SIKE07 & 우 & 2192 & 1308 & 2286 & 1350 & & & & \\
\hline WAMC55567 & KMWA.886 & & triangulata & SIKE07 & $\hat{0}$ & 1892 & 1161 & 1950 & 1158 & & & & \\
\hline OC3368 & KMWA.1364 & & triangulata & SIKE07 & 우 & & & & & 2190 & 1338 & & \\
\hline WAMC55569 & KMWA.1365 & & triangulata & SIKE07 & 우 & & & & & & & 2138 & 1122 \\
\hline WAMC55570 & KMWA.1366 & & triangulata & SIKE07 & 우 & & & & & & & 2168 & 1220 \\
\hline OC3369 & KMWA.1367 & & triangulata & SIKE07 & $\sigma^{\lambda}$ & & & & & 1818 & 1100 & & \\
\hline WAMC55571 & KMWA.1368 & & triangulata & SIKE07 & $\sigma^{\lambda}$ & & & & & & & 1917 & 1038 \\
\hline WAMC55572 & KMWA.1369 & & triangulata & SIKE07 & $\sigma^{\lambda}$ & & & & & & & 1933 & 1065 \\
\hline OC3367 & KMWA.244 & & triangulata & CB54 & 우 & 1931 & 1072 & 2147 & 1122 & & & & \\
\hline WAMC55574 & OS.254 & & triangulata & CB54 & $0^{\pi}$ & 1888 & 996 & 1990 & 1006 & & & & \\
\hline WAMC55575 & OS.122 & & triangulata & CB75a & $\widehat{0}$ & 1800 & 1075 & & & & & & \\
\hline WAMC55576 & KMWA.884 & & triangulata & SIKE11 & $0^{\lambda}$ & 1961 & 1022 & 2069 & 1061 & & & & \\
\hline WAMC55577 & KMWA.885 & & triangulata & SIKE11 & 우 & 2339 & 1300 & 2486 & 1297 & & & & \\
\hline WAMC55578 & KMWA.701 & & triangulata & SIKE21 & 우 & 2173 & 1360 & 2238 & 1377 & & & & \\
\hline WAMC55579 & KMWA.702 & & triangulata & SIKE21 & 우 & & & & & 2178 & 1331 & & \\
\hline WAMC55580 & KMWA.703 & & triangulata & SIKE21 & 우 & & & & & 2161 & 1350 & & \\
\hline no nr & KMWA.1189 & КР006594 & triangulata & ESKI01 & 우 & 1963 & 1230 & 2035 & 1255 & & & & \\
\hline no nr & KMWA.229 & & triangulata & OSTR10B & 우 & 2030 & 1100 & & & & & & \\
\hline no nr & KMWA.230 & & triangulata & OSTR10B & 우 & & & & & & & 2010 & 1030 \\
\hline no nr & KMWA.231 & & triangulata & OSTR10B & 우 & & & & & 2080 & 1160 & & \\
\hline no nr & KMWA.232 & & triangulata & OSTR10C & 우 & & & & & & & 2260 & 1250 \\
\hline no $\mathrm{nr}$ & KMWA.234 & & triangulata & OSTR10C & q & 2160 & 1360 & 2270 & 1410 & & & & \\
\hline OC3371 & KMWA.1037 & КР006566 & nimala & NT/12/01 & q & 1500 & 861 & 1640 & 962 & & & & \\
\hline WAMC55585 & KMWA.1038 & KP006565 & nimala & $\mathrm{NT} / 12 / 01$ & 우 & 1520 & 872 & 1700 & 958 & & & & \\
\hline OC3372 & KMWA.1039 & & nimala & NT/12/01 & 우 & & & & & & & 1730 & 1020 \\
\hline WAMC55586 & KMWA.1040 & & nimala & $\mathrm{NT} / 12 / 01$ & ㅇ & & & & & 1680 & 1710 & & \\
\hline WAMC55587 & KMWA.1043 & KP006569 & nimala & NT/12/03 & 우 & 1510 & 863 & 1630 & 954 & & & & \\
\hline WAMC55588 & KMWA.1044 & KP006570 & nimala & NT/12/03 & 우 & 1480 & 853 & 1630 & 946 & & & & \\
\hline WAMC55589 & KMWA.1047 & & nimala & $\mathrm{NT} / 12 / 01$ & 우 & 1546 & 902 & 1700 & 994 & & & & \\
\hline WAMC55590 & KMWA.1048 & KP006568 & nimala & NT/12/08 & 우 & 1554 & 906 & 1748 & 1012 & & & & \\
\hline WAMC55591 & KMWA.1111 & & nimala & CNJ R-109 & 우 & 1383 & 781 & 1479 & 867 & & & & \\
\hline WAMC55592 & KMWA.1112 & & nimala & CNJ R-109 & 우 & 1462 & 852 & 1567 & 904 & & & & \\
\hline WAMC55593 & KMWA.1113 & & nimala & CNJ R-109 & 우 & 1450 & 840 & 1585 & 942 & & & & \\
\hline WAMC55594 & KMWA.1114 & & nimala & CORN 9/v/09 & 우 & 1481 & 850 & 1594 & 937 & & & & \\
\hline OC3373 & KMWA.1116 & & nimala & CORN 9/v/09 & 우 & & & & & 1627 & 1010 & & \\
\hline WAMC55595 & KMWA.164 & & tirigie & SIEK4 & $\sigma^{\pi}$ & 1080 & 603 & 1190 & 650 & & & & \\
\hline WAMC55596 & KMWA.169 & & tirigie & SIEK4 & 운 & 1180 & 692 & 1300 & 737 & & & & \\
\hline
\end{tabular}


MARTENS K., HALSE S. \& SCHÖN I., Bennelongia lineages in Western Australia

\begin{tabular}{|c|c|c|c|c|c|c|c|c|c|c|c|c|c|}
\hline WAMC55597 & KMWA.168 & & tirigie & SIEK4 & $\hat{0}$ & & & & & 1090 & 603 & 1100 & 659 \\
\hline WAMC55598 & KMWA.165 & & tirigie & SIEK4 & q & & & & & & & 1290 & 800 \\
\hline WAMC55599 & KMWA.166 & & tirigie & SIEK4 & q & & & & & & & 1300 & 755 \\
\hline WAMC55600 & KMWA.167 & & tirigie & SIEK4 & q & & & & & 1280 & 724 & & \\
\hline WAMC55605 & KMWA.1169 & КР006532 & tirigie & ESKI06 & $\hat{0}$ & 1029 & 593 & & & & & & \\
\hline WAMC55606 & KMWA.1170 & & tirigie & ESKI06 & q & & & & & & & 1196 & 740 \\
\hline WAMC55607 & KMWA.1171 & & tirigie & ESKI06 & q & & & & & 1136 & 638 & & \\
\hline WAMC55608 & KMWA.1172 & & tirigie & ESKI06 & $\hat{\sigma}$ & & & & & 1063 & 603 & & \\
\hline WAMC55609 & KMWA.1173 & & tirigie & ESKI06 & $\hat{0}$ & & & & & & & 1042 & 597 \\
\hline WAMC55610 & KMWA.1176 & КР006539 & tirigie & ESKI08 & q & 1129 & 660 & & & & & & \\
\hline OC3374 & KMWA.1178 & & tirigie & ESKI08 & q & & & & & 1178 & 663 & & \\
\hline OC3375 & KMWA.1179 & & tirigie & ESKI08 & $\hat{0}$ & & & & & 1086 & 615 & & \\
\hline WAMC55611 & KMWA.171 & & koendersae & KIES1A & 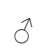 & 1110 & 587 & 1210 & 621 & & & & \\
\hline WAMC55612 & KMWA.174 & & koendersae & KIES1A & q & & & & & 1353 & 767 & 1340 & 845 \\
\hline WAMC55613 & KMWA.172 & & koendersae & KIES1A & $\hat{0}$ & & & & & 1190 & 629 & 1189 & 672 \\
\hline WAMC55614 & KMWA.175 & & koendersae & KIES1A & q & 1240 & 689 & 1340 & 729 & & & & \\
\hline OC3376 & KMWA.176 & & koendersae & KIES1A & q & 1260 & 714 & 1380 & 749 & & & & \\
\hline WAMC55617 & KMWA. 1260 & & koendersae & KIES1A & q & & & & & & & 1321 & 804 \\
\hline WAMC55618 & KMWA.1261 & & koendersae & KIES1A & q & & & & & & & 1309 & 725 \\
\hline WAMC55620 & KMWA.664 & & pinderi & SIKE03 & q & 1395 & 810 & 1507 & 840 & & & & \\
\hline WAMC55621 & KMWA.665 & & pinderi & SIKE03 & q & & & & & & & 1508 & 898 \\
\hline WAMC55622 & KMWA.666 & & pinderi & SIKE03 & q & & & & & 1450 & 810 & & \\
\hline OC3378 & KMWA.667 & & pinderi & SIKE03 & q & & & & & & & 1433 & 865 \\
\hline WAMC55624 & KMWA.671 & & pinderi & SIKE05 & q & 1410 & 813 & 1533 & 875 & & & & \\
\hline WAMC55625 & KMWA.672 & & pinderi & SIKE05 & o & & & & & & & 1528 & 927 \\
\hline WAMC55626 & KMWA.181 & & shieli & PSW036 & q & 1380 & 807 & 1467 & 888 & & & & \\
\hline WAMC55627 & KMWA.290 & & shieli & PSW036 & 우 & 1311 & 745 & 1475 & 852 & & & & \\
\hline OC3379 & KMWA.293 & & shieli & PSW036 & q & & & & & 1480 & 888 & & \\
\hline WAMC55628 & KMWA.183 & & shieli & PSW036 & q & & & & & & & 1500 & 933 \\
\hline WAMC55629 & KMWA.184 & & shieli & PSW036 & q & & & & & & & 1470 & 984 \\
\hline WAMC55630 & KMWA.294 & & shieli & PSW036 & q & 1370 & 813 & 1480 & 907 & & & & \\
\hline WAMC55632 & KMWA.1090 & & muggon & SIKE20 & q & 1015 & 603 & 1078 & 638 & & & & \\
\hline WAMC55633 & KMWA.1084 & & muggon & SIKE20 & q & 1018 & 606 & & & & & & \\
\hline WAMC55634 & KMWA.1085 & & muggon & SIKE20 & q & & & & & & & 1107 & 654 \\
\hline WAMC55635 & KMWA.1086 & & muggon & SIKE20 & q & & & & & 1117 & 668 & & \\
\hline WAMC55636 & KMWA.1087 & & muggon & SIKE20 & q & & & & & & & 1119 & 685 \\
\hline WAMC55637 & KMWA.690 & & muggon & SIKE20 & q & 1040 & 629 & 1108 & 655 & & & & \\
\hline WAMC55638 & KMWA.691 & & muggon & SIKE20 & ㅇ & & & & & & & 1111 & 699 \\
\hline WAMC55639 & KMWA.692 & & muggon & SIKE20 & q & & & & & & & 1101 & 681 \\
\hline WAMC55640 & KMWA.693 & & muggon & SIKE20 & q & & & & & 1078 & 660 & & \\
\hline WAMC55641 & KMWA.1345 & & muggon & SIKE20 & q & 1082 & 636 & & & & & & \\
\hline WAMC55642 & KMWA.1346 & & muggon & SIKE20 & q & 1021 & 603 & & & & & & \\
\hline WAMC55643 & KMWA.1347 & & muggon & SIKE20 & q & 1043 & 621 & 1111 & 650 & & & & \\
\hline OC3382 & KMWA.1348 & & muggon & SIKE20 & q & 1058 & 629 & 1124 & 667 & & & & \\
\hline OC3383 & KMWA.1349 & & muggon & SIKE20 & q & 1049 & 621 & 1121 & 672 & & & & \\
\hline WAMC55644 & KMWA.1350 & & muggon & SIKE20 & 우 & 1004 & 600 & 1056 & 631 & & & & \\
\hline
\end{tabular}


bootstrap replicates and the parameters of jModeltest for all 88 models), respectively. Genetic diversities and relationships within and between populations were illustrated with parsimonious networks at the $95 \%$ probability limit with TCS 1.21 (Clement et al. 2000). Selected sequences of all species have been submitted to Genbank (accession numbers KP006531-KP006599; see Table 1).

\section{Testing for cryptic diversity}

In the COI phylogenies of Bennelongia, well-supported phylogenetic clades (with bootstraps above 75\% or posterior probabilities above 0.85 ) were identified, which could represent different species following the evolutionary genetic species concept (Birky \& Barraclough 2009). We then used MEGA version 6.0 (Tamura et al. 2013) to estimate sequence diversities within and between these phylogenetic clades, either using the number of differences $(\mathrm{p})$ or the Tamura-3 parameter model with gamma distribution and 1000 bootstrap replicates. Following Birky et al. (2010), we then corrected the obtained estimates of sequence diversities for sample size. According to the 4 theta rule, sequence diversities between two sister clades must be no less than 4 to 4.3 times larger than within the two clades, depending on the number of sequences per clade (Birky et al. 2010). The 4 theta rule has been used previously on bdelloid rotifers (Fontaneto et al. 2007, 2009; Birky \& Barraclough 2009; Birky et al. 2011), sexual and asexual ostracods (Bode et al. 2010; Schön et al. 2012), including other Bennelongia species (Martens et al. 2012, 2013; Shearn et al. 2012), asexual prokaryotes (Birky et al. 2010) and sexual vertebrates and invertebrates (Birky 2013).

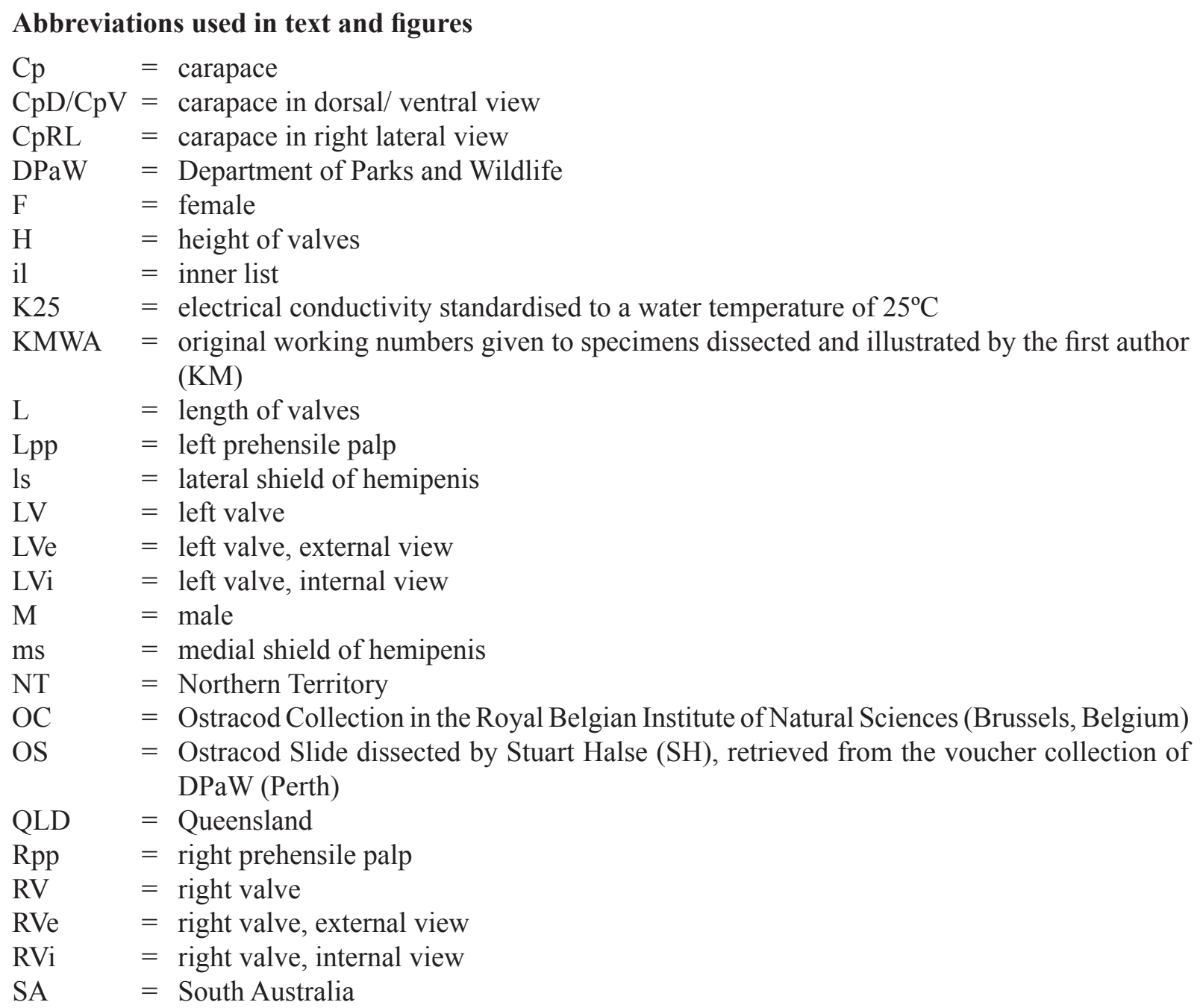


MARTENS K., HALSE S. \& SCHÖN I., Bennelongia lineages in Western Australia

$\begin{array}{ll}\text { Temp } & =\text { temperature in }{ }^{\circ} \mathrm{C} \\ \mathrm{W} & =\text { width of carapace } \\ \text { WA } & =\text { Western Australia } \\ \text { WAMC } & =\text { Western Australian Museum, Crustacean Collection (Perth, Australia) }\end{array}$

Specimens in bold in Table 1 represent the holotypes of the new species.

Chaetotaxy of the limbs follows the model proposed by Broodbakker \& Danielopol (1982), revised for A2 by Martens (1987). Higher taxonomy of the Ostracoda follows the synopsis by Horne et al. (2002).

\section{Results}

\section{Results of molecular screening}

Both phylogenetic methods generated COI trees with similar topologies consisting of seven wellsupported phylogenetic clades (see the consensus tree in Fig. 2). Of these seven clades, five, namely $B$. triangulata sp. nov., B. muggon sp. nov., B. koendersae sp. nov., B. pinderi sp. nov. and B. tirigie sp. nov., match with the novel species described here from morphological data (see below). A sixth clade

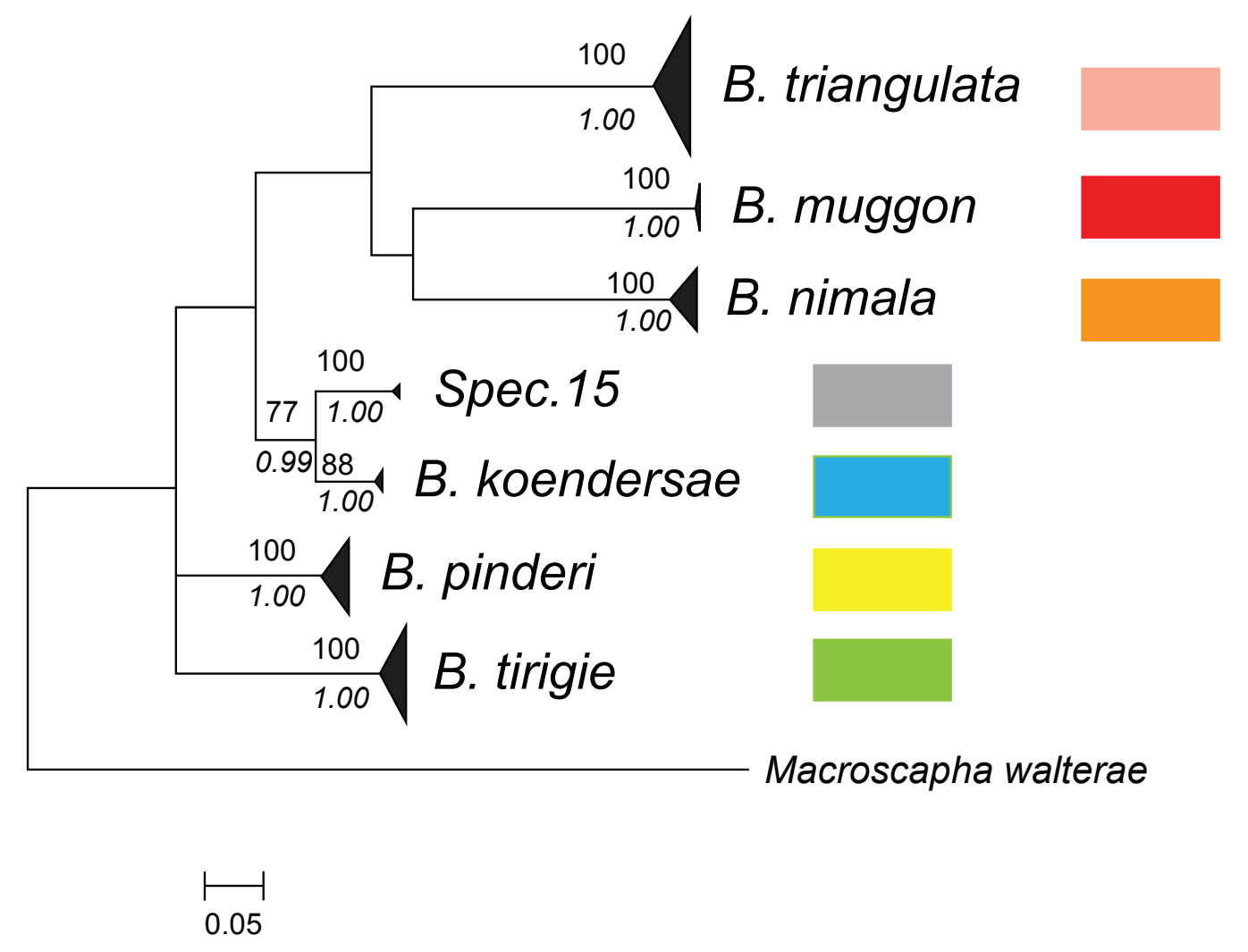

Fig. 2. Phylogenetic tree constructed with Bayesian Inference (BI) and Maximum Likelihood (ML) methods from COI sequences belonging to a total of 54 ostracods from the Bennelongia nimala and B. triangulata lineages, respectively, with the marine ostracod Macroscapha walterae from Genbank (accession number GU566887) as outgroup. Numbers above and below nodes illustrate statistical support for this particular node. Numbers above nodes are \% bootstrap values of ML analyses with 1000 replicates, numbers below nodes in italics represent Bayesian posterior probabilities (ranging from 0 to 1). Both methods, BI and ML, resulted in the same tree topology. Different phylogenetic clades are indicated by different colours. 


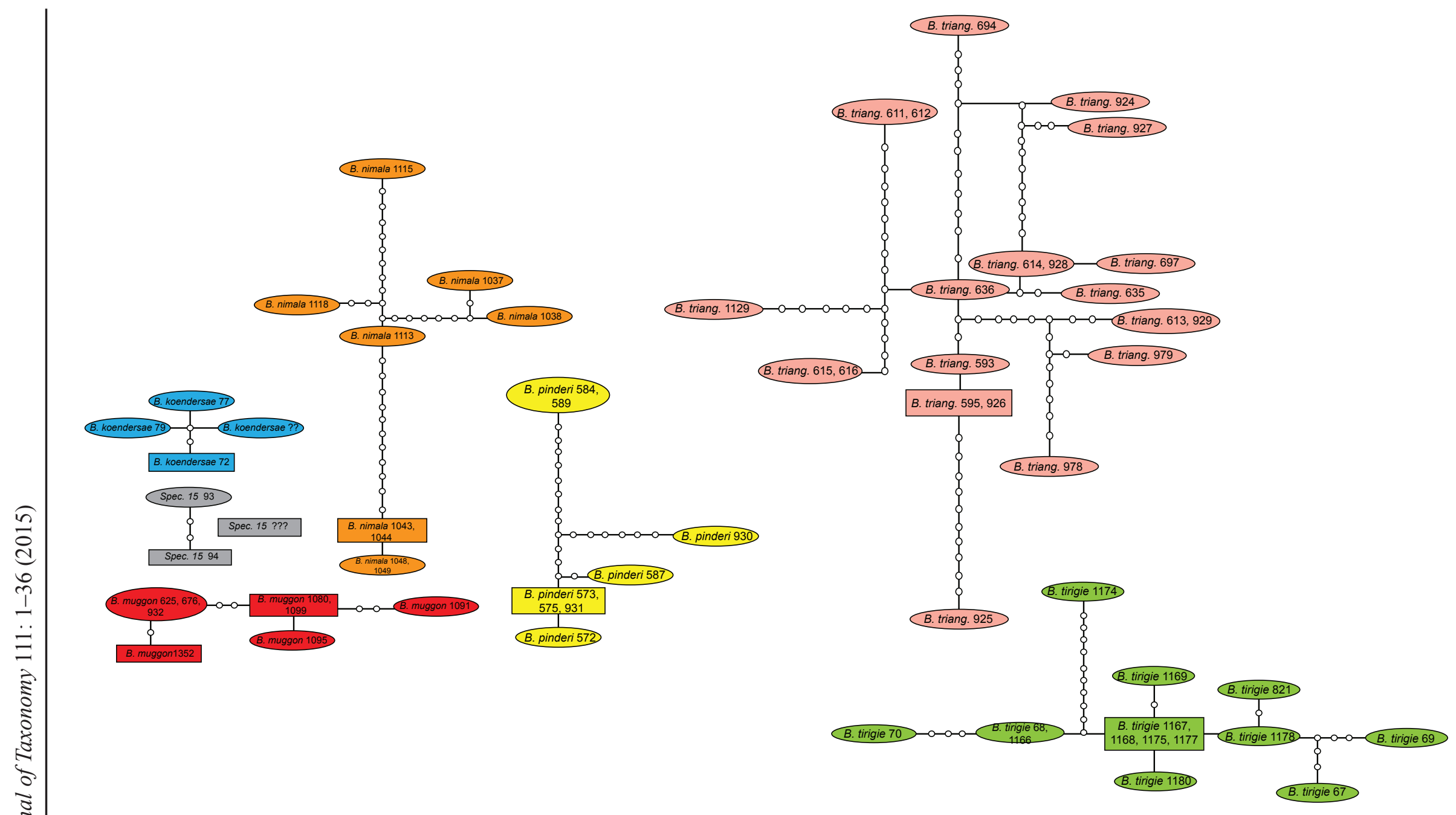

Fig. 3. Parsimonius networks, based on COI sequences of the Bennelongia nimala and B. triangulata lineages. Squares represent ancestral sequences (or haplotypes), small circles missing haplotypes. The size of squares and large ovals is proportional to the number of individuals with the same sequence in the analysed population. The networks were constructed with up to 14 mutations steps connecting different sequences or haplotypes. Different phylogenetic clades are indicated by different colours (see Fig. 2). 
Table 2. Results of tests for genetic species boundaries using the 4 theta rule for species of the Bennelongia nimala and $B$. triangulata lineages, respectively. $\theta=$ population genetic parameter theta, indicating genetic variability within populations. $D=$ genetic distance between sister clades. $n^{1}, n^{2}=$ number of sequences for each sister clade. $\theta$ and $\mathrm{D}$ were either calculated as $\mathrm{p}$ distances or with the Tamura-3 parameter model (in italics). With the exception of B. koendersae sp. nov. and Spec. 15 (see Fig. 2), no sister clades with high statistical support could be identified in the obtained COI trees; therefore, all phylogenetic clades were compared to each other. In order to fulfil the criteria of the 4 theta rule for genetic species status, the ratio of the mean sequence diversity within a phylogenetic clade (theta, $\theta$ ) as compared to the sequence diversity between this clade and its nearest phylogenetic neighbour (D) needs to be 4 or more, depending on the number of specimens per clade (Birky et al. 2010). Comparisons, for which these criteria are fulfilled, are printed in bold. (Table continued on next page.)

\begin{tabular}{|c|c|c|c|c|}
\hline Species & $\begin{array}{c}\text { max. } \theta \\
\text { (within clades) }\end{array}$ & $\begin{array}{c}\text { D } \\
\text { (between clades) }\end{array}$ & Ratio D/o & $\mathbf{n}^{1}, \mathbf{n}^{2}$ \\
\hline B. koendersae - Spec. 15 & $\begin{array}{l}0.0091 \\
0.0091\end{array}$ & $\begin{array}{l}0.049 \\
0.053\end{array}$ & $\begin{array}{l}5.38 \\
5.82\end{array}$ & 4,2 \\
\hline B. koendersae - B. tirigie & $\begin{array}{l}0.0081 \\
0.0083\end{array}$ & $\begin{array}{l}0.114 \\
0.135\end{array}$ & $\begin{array}{l}14.07 \\
16.27\end{array}$ & 4,14 \\
\hline B. koendersae - B. pinderi & $\begin{array}{l}0.0148 \\
0.0154\end{array}$ & $\begin{array}{l}0.106 \\
0.124\end{array}$ & $\begin{array}{l}7.16 \\
8.05\end{array}$ & 4,10 \\
\hline B. koendersae - B. nimala & $\begin{array}{l}0.0200 \\
0.0204\end{array}$ & $\begin{array}{l}0.124 \\
0.148\end{array}$ & $\begin{array}{l}6.20 \\
7.25\end{array}$ & 4,9 \\
\hline B. koendersae - B. muggon & $\begin{array}{l}0.0050 \\
0.0052\end{array}$ & $\begin{array}{l}0.137 \\
0.168\end{array}$ & $\begin{array}{l}27.40 \\
32.31\end{array}$ & 4,8 \\
\hline B. koendersae - B. triangulata & $\begin{array}{l}0.0189 \\
0.0196\end{array}$ & $\begin{array}{l}0.129 \\
0.157\end{array}$ & $\begin{array}{l}6.83 \\
8.01\end{array}$ & 4,21 \\
\hline Spec. $15-$ B. tirigie & $\begin{array}{l}0.0091 \\
0.0091\end{array}$ & $\begin{array}{l}0.113 \\
0.133\end{array}$ & $\begin{array}{l}12.42 \\
14.62\end{array}$ & 2,14 \\
\hline Spec. $15-B$. pinderi & $\begin{array}{l}0.0148 \\
0.0154\end{array}$ & $\begin{array}{l}0.097 \\
0.112\end{array}$ & $\begin{array}{l}6.55 \\
7.27\end{array}$ & 2,10 \\
\hline Spec. $15-B$. nimala & $\begin{array}{l}0.0200 \\
0.0204\end{array}$ & $\begin{array}{l}0.140 \\
0.171\end{array}$ & $\begin{array}{l}7.00 \\
8.38\end{array}$ & 2,9 \\
\hline Spec. 15 - B. muggon & $\begin{array}{l}0.0091 \\
0.0091\end{array}$ & $\begin{array}{l}0.143 \\
0.177\end{array}$ & $\begin{array}{l}15.71 \\
19.45\end{array}$ & 2,8 \\
\hline Spec. $15-$ B. triangulata & $\begin{array}{l}0.0189 \\
0.0196\end{array}$ & $\begin{array}{l}0.137 \\
0.170\end{array}$ & $\begin{array}{l}7.25 \\
8.67\end{array}$ & 2,21 \\
\hline B. pinderi - B. tirigie & $\begin{array}{l}0.0148 \\
0.0154\end{array}$ & $\begin{array}{l}0.109 \\
0.128\end{array}$ & $\begin{array}{l}7.36 \\
8.31\end{array}$ & 10,14 \\
\hline B. pinderi $-B$. nimala & $\begin{array}{l}0.0200 \\
0.0204\end{array}$ & $\begin{array}{l}0.159 \\
0.204\end{array}$ & $\begin{array}{c}7.95 \\
10.00\end{array}$ & 10,9 \\
\hline
\end{tabular}




\begin{tabular}{|c|c|c|c|c|}
\hline B. pinderi-B. muggon & $\begin{array}{l}0.0148 \\
0.0157\end{array}$ & $\begin{array}{l}0.148 \\
0.186\end{array}$ & $\begin{array}{l}10.00 \\
11.85\end{array}$ & 10,8 \\
\hline B. pinderi $-B$. triangulata & $\begin{array}{l}0.0189 \\
0.0196\end{array}$ & $\begin{array}{l}0.144 \\
0.181\end{array}$ & $\begin{array}{l}7.62 \\
9.23\end{array}$ & 10,21 \\
\hline B. tirigie - B. nimala & $\begin{array}{l}0.0200 \\
0.0204\end{array}$ & $\begin{array}{l}0.146 \\
0.184\end{array}$ & $\begin{array}{l}7.30 \\
9.02\end{array}$ & 14,9 \\
\hline B. tirigie - B. muggon & $\begin{array}{l}0.0081 \\
0.0083\end{array}$ & $\begin{array}{l}0.142 \\
0.177\end{array}$ & $\begin{array}{l}17.53 \\
21.33\end{array}$ & 14,8 \\
\hline B. tirigie $-B$. triangulata & $\begin{array}{l}0.0189 \\
0.0196\end{array}$ & $\begin{array}{l}0.136 \\
0.167\end{array}$ & $\begin{array}{l}7.20 \\
8.52\end{array}$ & 14,21 \\
\hline B. nimala - B. muggon & $\begin{array}{l}0.0200 \\
0.0204\end{array}$ & $\begin{array}{l}0.144 \\
0.177\end{array}$ & $\begin{array}{l}7.20 \\
8.68\end{array}$ & 9,8 \\
\hline B. nimala - B. triangulata & $\begin{array}{l}0.0200 \\
0.0204\end{array}$ & $\begin{array}{l}0.142 \\
0.175\end{array}$ & $\begin{array}{l}7.10 \\
8.58\end{array}$ & 9,21 \\
\hline B. muggon - B. triangulata & $\begin{array}{l}0.0189 \\
0.0196\end{array}$ & $\begin{array}{l}0.146 \\
0.179\end{array}$ & $\begin{array}{l}7.72 \\
9.13\end{array}$ & 8,21 \\
\hline
\end{tabular}

contains the sequences of $B$. nimala (see below). Two additional sequences in the tree belonging to clade Spec. 15 could not be investigated morphologically because the entire specimens had been used for the molecular analyses. The sequences of Spec. 15 cluster together with B. koendersae sp. nov. with good statistical support while the relationships among the other phylogenetic clades cannot be derived from the COI tree because of lack of statistical support (Fig. 2). The seven phylogenetic clades are completely congruent with seven isolated parsimonious networks (Fig. 3). Among the network structures, it appears that $B$. triangulata sp. nov. is genetically most diverse, as this species contains 16 different haplotypes (sequences) being separated by up to 15 mutational steps. With 10 haplotypes, the network of $B$. tirigie sp. nov. is genetically the second most diverse species while the other species contain 7 ( $B$. nimala), 5 (B. pinderi sp. nov.) and 4 (B. koendersae sp. nov. and B. muggon sp. nov.) haplotypes, respectively, and their network structures are more simple. When comparing genetic diversities between and within each phylogenetic clade, the genetic distances between all seven phylogenetic clades clearly exceed the distances within each clade by more than 4 times (Table 2), thus fulfilling the criterion of the 4 theta rule (Birky et al. 2010). The seven phylogenetic clades and networks can thus be regarded as different genetic species according to the phylogenetic species concept. We found no evidence for cryptic genetic diversity as all genetic species matched the morphological species with the exception of Spec. 15, for which no morphological data are available. 
MARTENS K., HALSE S. \& SCHÖN I., Bennelongia lineages in Western Australia

\title{
Taxonomic descriptions
}

\author{
Class Ostracoda Latreille, 1806 \\ Subclass Podocopa G.O. Sars, 1866 \\ Order Podocopida G.O. Sars, 1866 \\ Suborder Cypridocopina Baird, 1845 \\ Superfamily Cypridoidea Baird, 1845 \\ Family Cyprididae Baird, 1845 \\ Subfamily Bennelongiinae Martens et al., 2012
}

Genus Bennelongia De Deckker \& McKenzie, 1981

\section{Diagnosis}

See Martens et al. (2012).

\section{Bennelongia nimala - lineage}

\section{Diagnosis of the $B$. nimala-lineage}

All species in this lineage with strongly calcified and heavily ornamented valves, also in adults external valve surfaces set with large pustules, spines and short but stiff setae. Nearly all species with yellowishbrownish colour. Most species also with very pronounced anterior LV/RV overlap, most pronounced of all lineages in this genus. Some species with an inner 'eyelet' in the anterior part of the RV, close to the lapel, just as in the species of the B. barangaroo lineage (see Martens et al. 2013), to which this lineage is most closely related.

\section{Bennelongia nimala De Deckker, 1981}

Fig. $4 \mathrm{~A}-\mathrm{N}$

Bennelongia nimala n. sp. - De Deckker, 1981: 105-108, figs 10-11.

\begin{abstract}
Abbreviated redescription.
Valves in inner view (Fig. 4A-B) relatively high, with almost straight dorsal margin and greatest height situated well in front of the middle; ventral margin anteriorly without mandibular curve. LV (Fig. 4A) with antero-distal il running all the way down into the beak, but not connecting with ventral inner list; antero-proximal il running slightly over halfway along the anterior margin; posterior il tuberculate and running halfway up the posterior margin, next to the pointed valve margin. RV (Fig. 4B) with anteroventral lapel large, ventrally pointed and heavily serrated (Fig. 4L-N). Both valves with heavy external ornamentation, consisting of pits, smaller and larger tubercles (Fig. 4C-D, F-G, K).

Cp (Fig. 4G, K, M) with LV overlapping RV on all sides, but moderately so; CpRL with LV forming an antero-dorsal hump over RV. CpD with greatest width situated in the middle in females (Fig. 4G), anteriorly with strong and slightly asymmetrical rostrum, dorsally set with parallel rows of tubercles.

From De Deckker (1981): Soft parts as typical of the genus. Hemipenis with lobe ls broad and plump, antero-ventral extremity broadly rounded; lobe ms with antero-ventral extremity broad and rounded. Rpp with unusually long and narrow distal segment. Lpp with sickle-shaped terminal segment, relatively long and slender, also proximal segment long and narrow.
\end{abstract}




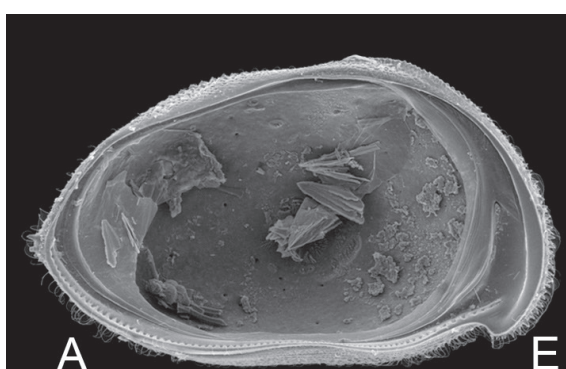

A

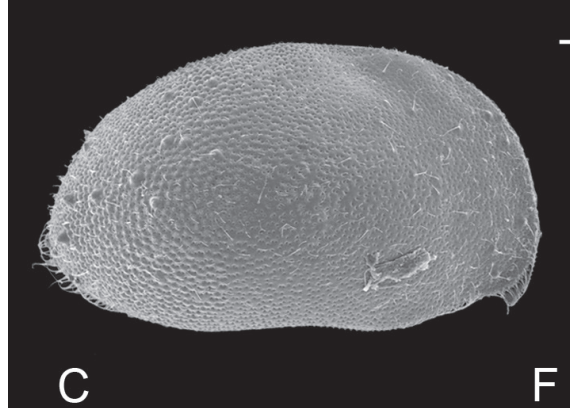

$\mathrm{F}$

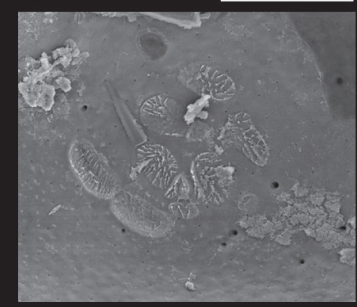

$200 \mu \mathrm{m}$

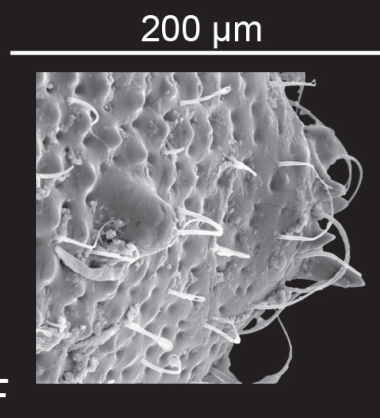

- Dileser.

B
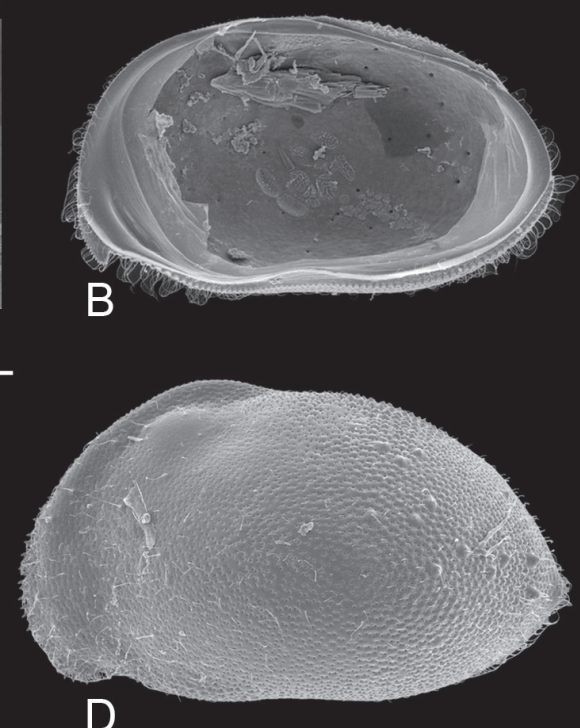

D
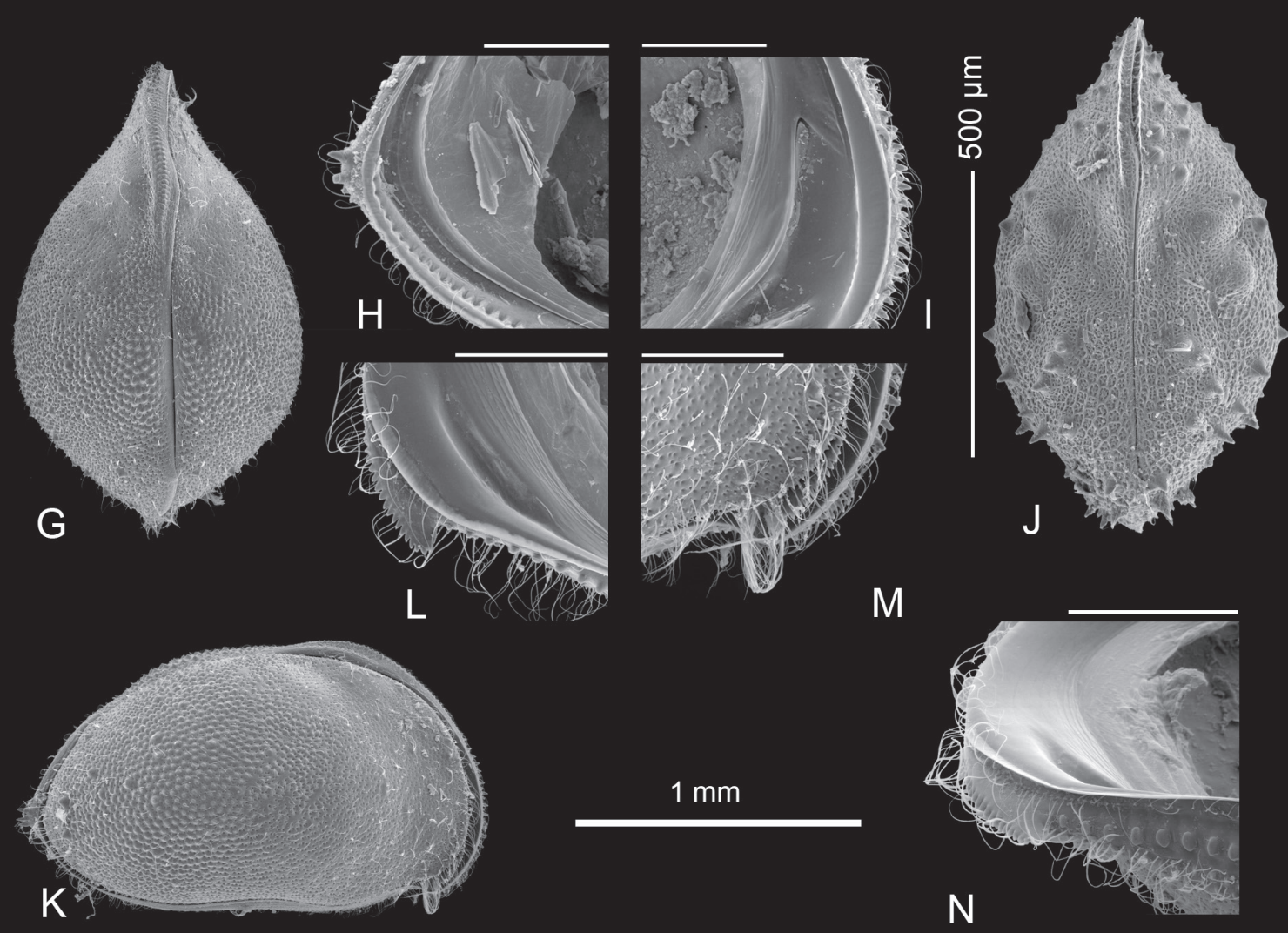

M

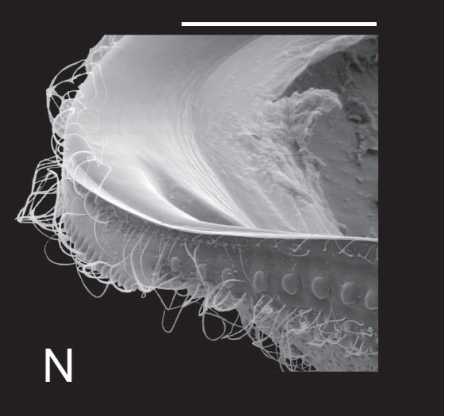

Fig. 4. Bennelongia nimala De Deckker, 1981 (all 9 , all from Kakadu National Park, NT). A. LVi (WAMC55593). B. RVi (WAMC55593). C. RVe (WAMC55589). D. LVe (WAMC55589). E. RVi, detail of central muscle scars (WAMC55593). F. LVe, detail of surface ornamentation (WAMC55589). G. CpD (OC3373). H. LVi, detail of caudal side (WAMC55593). I. LVi, detail of anterior side (WAMC55593). J. CpD (juvenile A-3, specimen lost). K. CpRL (OC3373). L. RVi, detail of anterior margin (WAMC55593). M. CpRL, detail of anterior margin, showing external view of lapel (OC3373). N. RVi, tilted, detail of anterior margin and of lapel (WAMC55593). Scale = $1 \mathrm{~mm}$ for A-D, G, K; 500 $\mu \mathrm{m}$ for $\mathrm{J} ; 200 \mu \mathrm{m}$ for $\mathrm{E}-\mathrm{F}, \mathrm{H}-\mathrm{I}, \mathrm{L}-\mathrm{N}$. 
MARTENS K., HALSE S. \& SCHÖN I., Bennelongia lineages in Western Australia

\section{New material investigated}

Kakadu National Park, Coonjimba Billabong, Gulungul Creek, Ranger, Jabiru region, NT (sample CNJ-R-109). Approximate coordinates: 12³4'37” S, 13252'30.1” E. Collected by Russell Shiel on 9 May 2009. Several females (WAMC55591-55593).

Kakadu National Park, Corndori Billabong, Gulungul Creek, Ranger, Jabiru region, NT (sample CORN 9/v/09). Approximate coordinates: $12^{\circ} 37^{\prime} 50^{\prime \prime} \mathrm{S}, 120^{\circ} 53^{\prime} 06^{\prime \prime} \mathrm{E}$. Collected by Russell Shiel on 9 May 2009. Several females (WAMC55594, OC3373).

Unnamed lagoon, Adelaide River Floodplain, NT (sample NT/12/01). Approximate coordinates: $12^{\circ} 53^{\prime} 06.5^{\prime \prime} \mathrm{S}, 131^{\circ} 12^{\prime} 03.0^{\prime \prime}$ E. Collected by the authors on 28 Jul. 2012. Several females (OC33713372, WAMC55585-55586, 55589). $\mathrm{K} 25=58 \mu \mathrm{S} / \mathrm{cm}, \mathrm{Temp}=30,2^{\circ} \mathrm{C}, \mathrm{pH}=8.0$, depth $=c a .0 .3 \mathrm{~m}$.

Bennett Dam, Adelaide River Floodplain, NT (sample NT/12/03). Approximate coordinates: $12^{\circ} 57^{\prime} 08.3^{\prime \prime}$ S, $131^{\circ} 09^{\prime} 59.7^{\prime \prime}$ E. Collected by the authors on 25 Jul. 2012. Several females (WAMC55587-55588). $\mathrm{K} 25=58 \mu \mathrm{S} / \mathrm{cm}, \mathrm{Temp}=28^{\circ} \mathrm{C}, \mathrm{pH}=7.2$, depth $=c a .0 .5 \mathrm{~m}$.

Unnamed lagoon, Mary River Park, NT (sample NT/12/08). Approximate coordinates: 1254'52.1” S, 131'39'23.7”' E. Collected by the authors on 26 Jul. 2012. Several females (WAMC55590).

\section{Type locality}

Georgetown Lagoon, Jabiru, NT.

Measurements (all measurements in $\mu \mathrm{m}$ - see Table 1 for measurements of all newly collected specimens illustrated with SEM)

Measurements of type material from De Deckker (1981):

Holotype ${ }^{7}: \mathrm{RV}: \mathrm{L}=1340, \mathrm{H}=760, \mathrm{LV}: \mathrm{L}=1500, \mathrm{H}=840$.

Paratype ( : RV: $\mathrm{L}=1540, \mathrm{H}=860 ; \mathrm{LV}: \mathrm{L}=1640, \mathrm{H}=960$.

Measurements of new material (only $q$ q 9 ):

$\mathrm{RV}: \mathrm{L}=1450-1550, \mathrm{H}=780-900 ; \mathrm{LV}: \mathrm{L}=1480-1750, \mathrm{H}=870-1010, \mathrm{~W}=c a .1020$.

\section{Differential diagnosis}

The species can be separated from all other congeners belonging to the B. nimala lineage by the pointed caudal section of the LV and by the large, pronounced and heavily serrated lapel on the RV. The moderate antero-ventral LV/RV overlap distinguishes this species specifically from $B$. tirigie sp. nov., $B$. koendersae sp. nov. and B. muggon sp. nov.

\section{Ecology and distribution}

Bennelongia nimala is an NT species. It occurs in vegetated and unvegetated freshwater lagoons, from which it derives its name.

Bennelongia tirigie sp. nov. urn:1sid:zoobank.org:act:7323D117-25B3-4059-B42C-079286494218

Figs $5 \mathrm{~A}-\mathrm{N}, 6 \mathrm{~A}-\mathrm{D}$

\section{Abbreviated description}

Valves in inner view (Fig. 5A, C-D, F) relatively elongated, with rounded dorsal margin and greatest height situated well in front of the middle; ventral margin with pronounced mandibular curve anteriorly. 
LV (Fig. 5A, D) with antero-distal il running only halfway along the anterior valve margin, anteroproximal il running almost all the way up along the valve margin; posterior il tuberculate and running halfway up the posterior margin. RV (Fig. 5C, F) with antero-ventral lapel relatively large, but bent closely to valve surface and therefore less conspicuous (Fig. $5 \mathrm{~K}-\mathrm{N}$ ). Valves with heavy external ornamentation, mostly consisting of small tubercles (Fig. 5B, E, G-J).

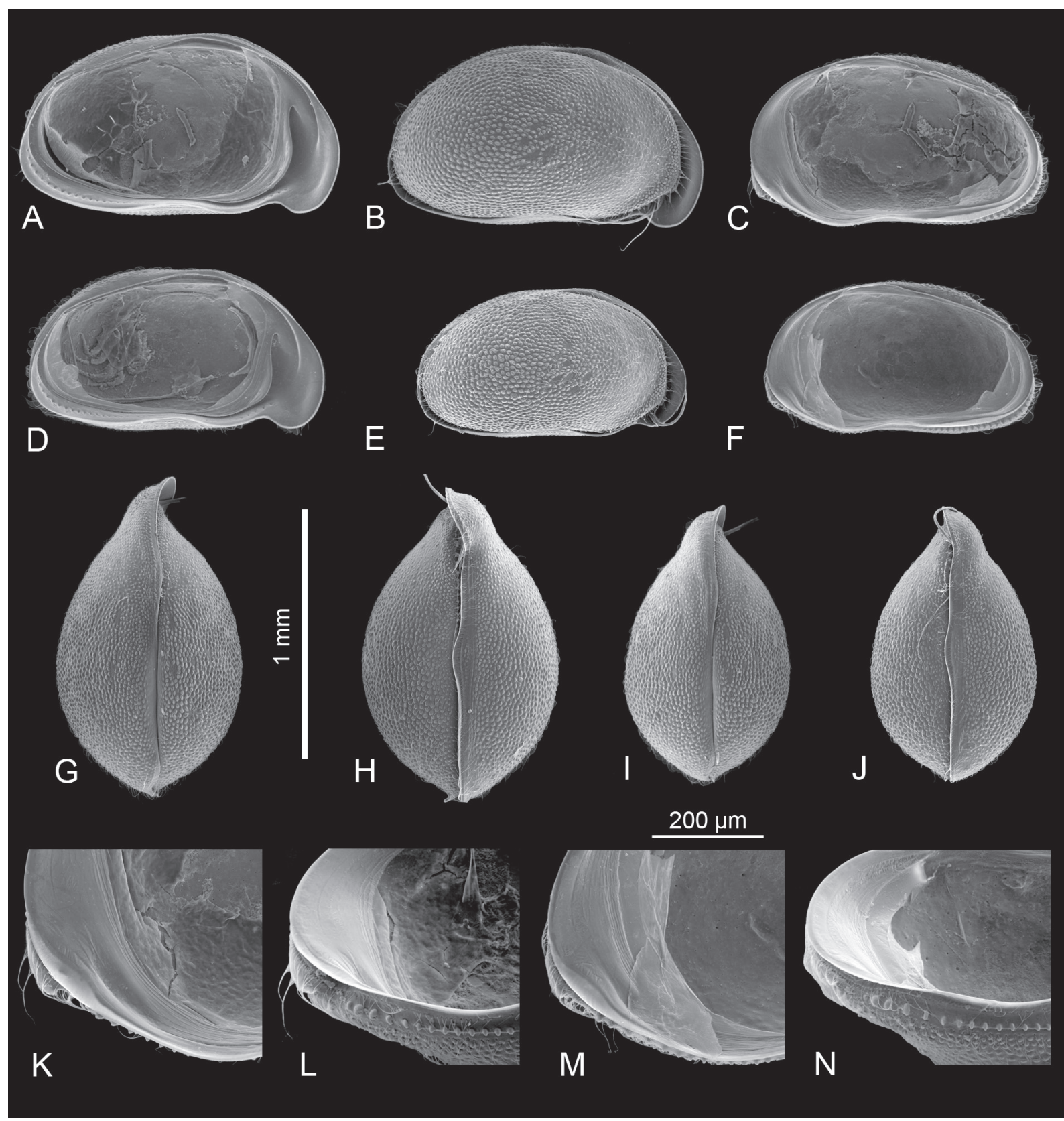

Fig. 5. Bennelongia tirigie sp. nov. (all from type locality: Tirigie Claypan, Murchison/Gascoyne, WA). A. LVi (allotype $q$, WAMC55596). B. CpRL (, WAMC 55600). C. RVi (, WAMC55596). D. LVi (holotype $\hat{\partial}$, WAMC55595). E. CpRL (ô, WAMC55597). F. RVi (ò, WAMC55595). G. $\mathrm{CpD}$ ( + , WAMC55599). H. CpV (, WAMC55598). I. CpD (o, WAMC55597). J. CpV (o, WAMC55597). K. RVi, detail anterior margin (क, WAMC55596). L. RVi, tilted, detail anterior margin (, WAMC55596). M. RVi, detail anterior margin (ð, WAMC55595). N. RVi, tilted, detail anterior margin ( ${ }^{\lambda}$, WAMC55595). Scale $=1 \mathrm{~mm}$ for A-J; $200 \mu \mathrm{m}$ for $\mathrm{K}-\mathrm{N}$. 
Cp (Fig. 5B, E, G-J) with largest LV/RV overlap of all Bennelongia species known to date. CpD and $\mathrm{CpV}$ with greatest width situated slightly behind the middle in males (Fig. 5I-J), in the middle in females (Fig. 5G-H), anteriorly with strong and asymmetrical rostrum.

Soft parts as typical of the genus. Hemipenes (Fig. 6A-B) almost symmetrical, edge of lobe ms almost straight, lobe 1s with extremity ventrally pointed. Lpp (Fig. 6C) with distal segment rather narrow. Rpp (Fig. 6D) with distal segment rather broad, elongated and distally rounded, sensory organ on first segment stout.

\title{
Etymology
}

The species is named after its type locality, Tirigie Claypan in Gascoyne, WA.

\section{Type material}

\section{Holotype}

$\hat{\sigma}$ (WAMC55595), with soft parts dissected in a sealed slide and valves stored dry in a micropalaeontological slide.

\author{
Allotype \\ o (WAMC55596), with valves stored dry in a micropalaeontological slide and soft parts used for \\ molecular screening.
}

\section{Paratypes}

Numerous females and males from the type locality, either dissected or stored as the holotype, as carapaces used for SEM or in alcohol. See Table 1 for listing of specimens (WAMC5597-55601).

\section{Other material investigated}

Crackers Swamp, Dandaragan, WA (sample SIEK1). Approximate coordinates: 3054’36” S, $115^{\circ} 35^{\prime} 30.2^{\prime \prime}$ E. All material collected by the authors on 5 Apr. 2006. Several females.

Minilya Pool, Gascoyne, WA (sample SIKE19). Approximate coordinates: 235'ㄹ' $5^{\prime \prime}$ S, $114^{\circ} 01^{\prime} 47.3^{\prime \prime}$ E. All material collected by the authors on $7 \mathrm{Jul} .2011 . \mathrm{K} 25=693 \mu \mathrm{S} / \mathrm{cm}, \mathrm{Temp}=17.3^{\circ} \mathrm{C}, \mathrm{pH}=7.3$.

Unnamed crabhole swamp on Winning Station, Gascoyne, WA (sample ESKI05). Approximate coordinates: $23^{\circ} 15^{\prime} 22^{\prime \prime} \mathrm{S}, 114^{\circ} 44^{\prime} 57.8^{\prime \prime}$ E. All material collected by the authors on 6 Apr. 2013. Several females (WAMC55602-55604).

Dam on Winning Station, Gascoyne, WA (sample ESKI06). Approximate coordinates: $22^{\circ} 14^{\prime} 16.0^{\prime \prime}$ S, $114^{\circ} 42^{\prime} 34.0^{\prime \prime}$ E. All material collected by the authors on 6 Apr. 2013. Several males and females (WAMC556055-55609).

Unnamed large claypan on Winning Station, Gascoyne, WA (sample ESKI08). Approximate coordinates: $2^{\circ} 07^{\prime} 39.6^{\prime \prime} \mathrm{S}, 114^{\circ} 34^{\prime} 41.3^{\prime \prime}$ E. All material collected by the authors on 6 Apr. 2013. Several males and females (WAMC55610, OC3374-3375).

\section{Type locality}

AUSTRALIA: Tirigie Claypan, Gascoyne, WA (sample SIEK4), approximate coordinates: 2438'29" S, $113^{\circ} 59^{\prime} 44^{\prime \prime}$ E. All material collected by the authors on 7 Apr. 2006. 


\title{
Differential diagnosis
}

The large frontal LV/RV overlap and the shape of the lapel on the RV distinguish this species from all others in the B. nimala lineage. The shape of the ls on the hemipenes and of the distal segment of the Rpp enables this species to be distinguished from others of the $B$. nimala lineage for which males are known: B. nimala has a broader ls and an even narrower distal segment on the Rpp; $B$. koendersae sp. nov. has an ls that is longer, more robust and not so pointed, while the distal segment of its Rpp is broadly triangular, with almost straight margins; in B. regina Shearn et al., 2012 the distal segment of the Rpp is evenly rounded while the ls of the hemipenes end in small, birdhead-like lobes.

Measurements (all measurements in $\mu \mathrm{m}$ - see Table 1 for measurements of all specimens illustrated with SEM)

Holotype $\widehat{\partial}$ (WAMC55595): RV: $\mathrm{L}=1080, \mathrm{H}=603$; LV: $\mathrm{L}=1190, \mathrm{H}=650$.

Allotype + (WAMC55596): $\mathrm{RV}: \mathrm{L}=1180, \mathrm{H}=692 ; \mathrm{LV}: \mathrm{L}=1300, \mathrm{H}=737$.

\section{Ecology and distribution}

Bennelongia tirigie sp. nov. is a common species in turbid seasonal water bodies of the Gascoyne region of WA. Its range extends south to the northern Swan Coastal Plain, where it has been collected from a seasonal freshwater swamp of low turbidity.

Bennelongia koendersae sp. nov. urn:1sid:zoobank.org:act:6CA91421-02FF-4A2E-A0E6-89F417057C81

Figs $6 \mathrm{E}-\mathrm{H}, 7 \mathrm{~A}-\mathrm{N}$

\begin{abstract}
Abbreviated description
Valves in inner view (Fig. 7A, C-D, F) relatively elongated, with rounded dorsal margin and greatest height situated well in front of the middle; ventral margin anteriorly without pronounced mandibular curve. LV (Fig. 7A, D) with antero-distal il running only halfway along the anterior valve margin, antero-proximal il running slightly higher along the anterior valve margin; posterior il tuberculate and running halfway up the posterior margin. RV (Fig. 7C, F) with antero-ventral lapel large, rounded and strongly serrated (Fig. $7 \mathrm{~K}-\mathrm{N}$ ). Valves with heavy external ornamentation, mostly consisting of small tubercles (Fig. 7B, E, G-J).
\end{abstract}

Cp (Fig. 7B, E, G-J) with large LV/RV overlap, but less so than in B. tirigie sp. nov. CpD and $\mathrm{CpV}$ with greatest width situated in the middle in males (Fig. $7 \mathrm{G}-\mathrm{H}$ ), slightly behind the middle in females (Fig. 7I-J), anteriorly with strong and asymmetrical rostrum.

Soft parts as typical of the genus. Hemipenes (Fig. 6E-F) almost symmetrical, edge of ms slightly sinuous, ls with extremity rounded. Lpp (Fig. 6G) with distal segment rather broad, distal half of second segment with parallel margins. Rpp (Fig. 6H) with distal segment large, subtriangular and with almost straight margins, sensory organ on first segment stout.

\section{Etymology}

The species is named after Dr Annette Koenders (Edith Cowan University, Joondalup, WA), in recognition of her contribution to our knowledge of the genetic diversity of various Australian invertebrate groups.

\section{Type material}

Holotype

$\widehat{\partial}$ (WAMC55611), with soft parts dissected in a sealed slide and valves stored dry in a micropalaeontological slide. 


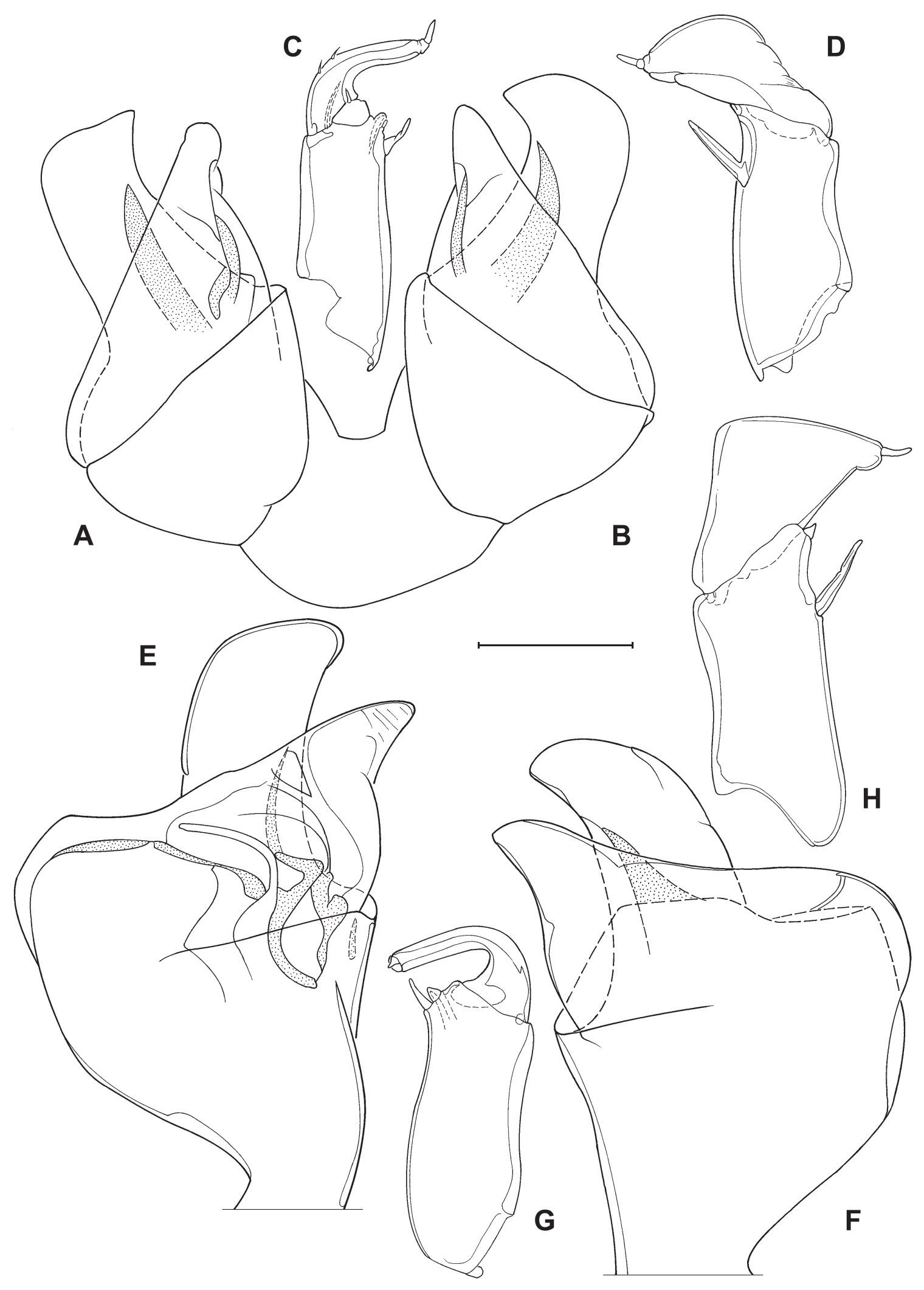

Fig. 6. Bennelongia tirigie sp. nov. (A-D, WAMC55595, holotype) and B. koendersae sp. nov. (EH, WAMC55615, paratype), all O. A-B. Outlines of hemipenes. C. Lpp. D. Rpp. E-F. Outlines of hemipenes. G. Lpp. H. Rpp. Scale $=73 \mu \mathrm{m}$ for A, D-E; $31 \mu \mathrm{m}$ for B-C, F-H. 


\section{Allotype}

o (WAMC55612) carapace stored dry in a micropalaeontological slide.

\section{Paratypes}

Numerous males and females from the type locality, either dissected and stored as the holotype, as carapaces used for SEM or in alcohol (WAMC55613-55619, OC3376-3377). See Table 1 for listing of specimens.

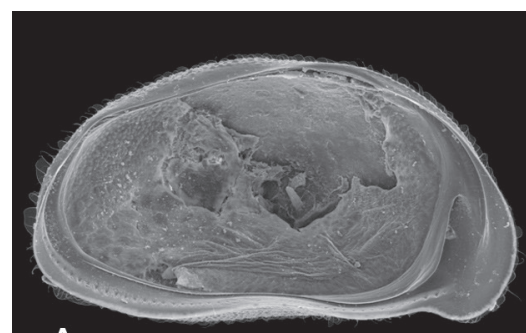

A

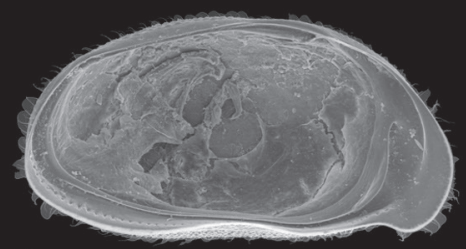

D
B
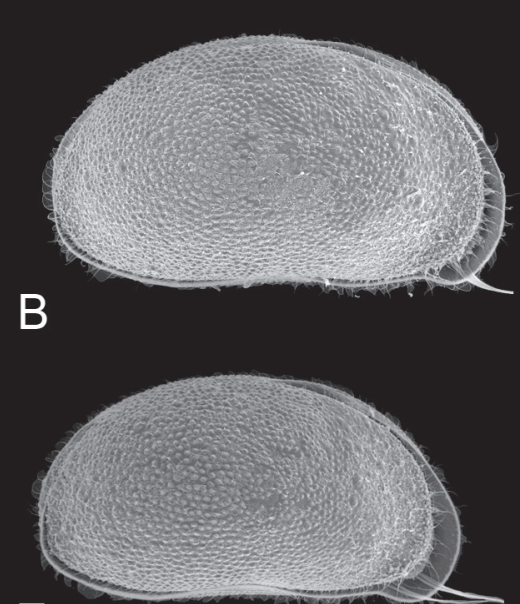

E

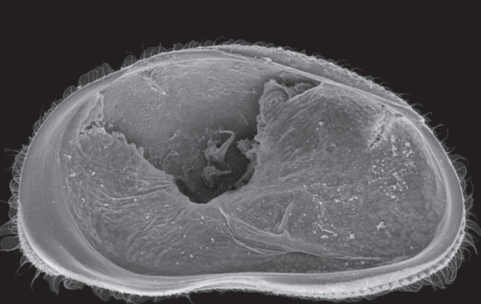

C

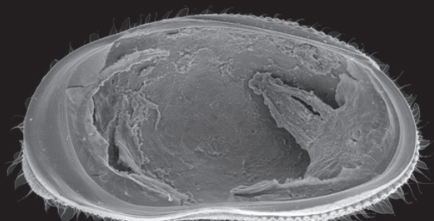

$\mathrm{F}$

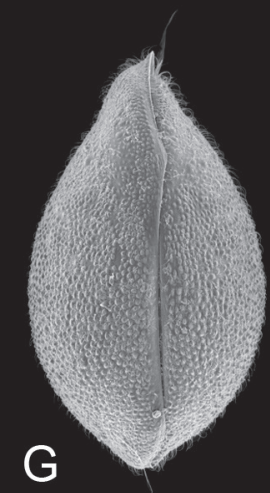

G

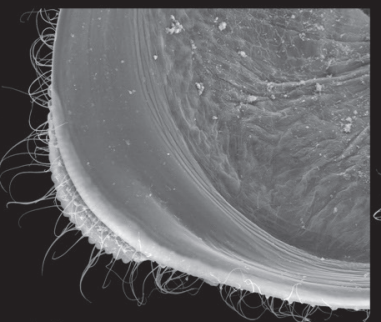

$\mathrm{K}$

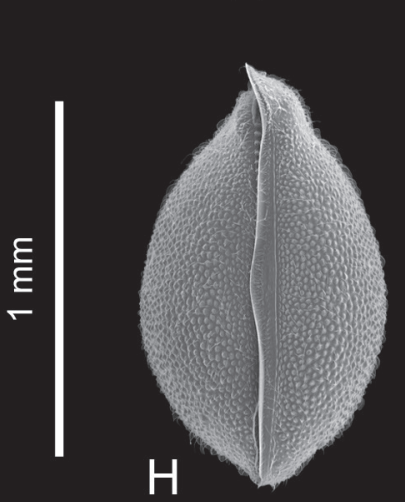

$\mathrm{H}$

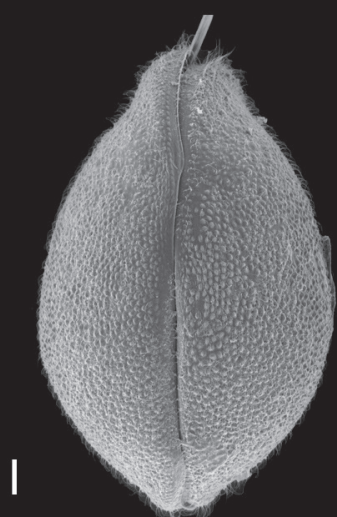

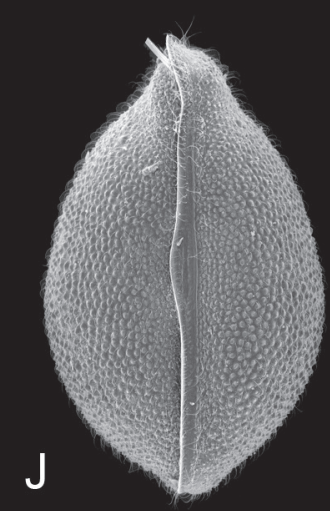
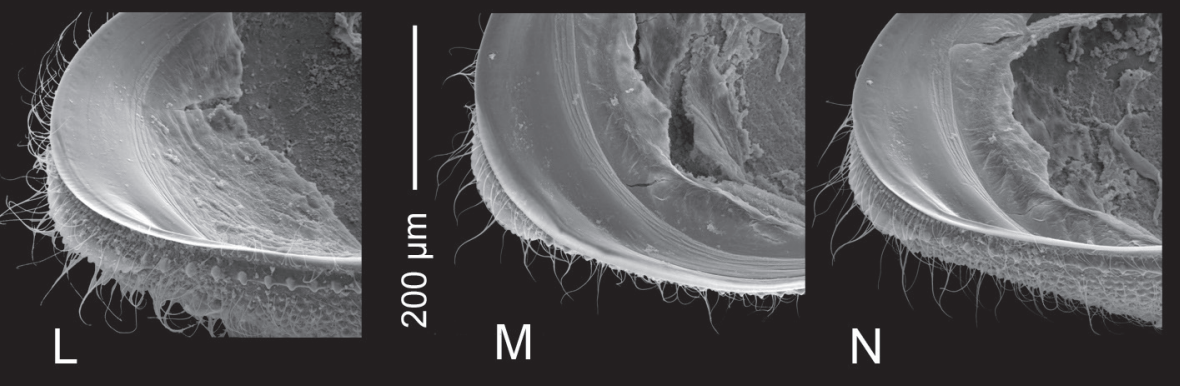

Fig. 7. Bennelongia koendersae sp. nov. (all from type locality: claypan at Strelley Station, Pilbara, WA). A. LVi (q, OC3376). B. CpRL (, WAMC55618). C. RVi (q, OC3376). D. LVi (holotype ${ }^{7}$, WAMC55611). E. CpRL (ふ, WAMC55613). F. RVi (ð, WAMC55611). G. CpD (ð, WAMC55613). H. CpV (ô, specimen lost). I. CpD (allotype $q$, WAMC55612). J. CpV ( + , WAMC55617). K. RVi, detail anterior margin ( 9, OC3376). L. RVi, tilted, detail anterior margin ( 9, OC3376. M. RVi, detail

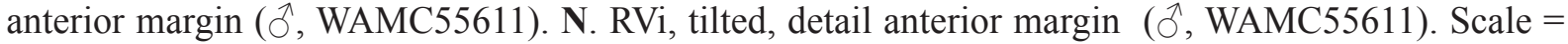
$1 \mathrm{~mm}$ for A-J; $200 \mu \mathrm{m}$ for $\mathrm{K}-\mathrm{N}$. 
MARTENS K., HALSE S. \& SCHÖN I., Bennelongia lineages in Western Australia

\title{
Type locality
}

AUSTRALIA: Strelley Station, shallow unnamed claypan, Pilbara, WA (sample KIES1A), approximate coordinates: $20^{\circ} 24^{\prime} 58^{\prime \prime}$ S, $118^{\circ} 59^{\prime} 4^{\prime \prime}$ E. All material collected by the authors on 21 Apr. 2006.

Measurements (all measurements in $\mu \mathrm{m}$ - see Table 1 for measurements of all specimens illustrated with SEM)

Holotype $\widehat{\partial}$ (WAMC55611): $\mathrm{RV}: \mathrm{L}=1110, \mathrm{H}=587 ; \mathrm{LV}: \mathrm{L}=1210, \mathrm{H}=621$.

Paratype + (WAMC55612): RV: $\mathrm{L}=1240, \mathrm{H}=689 ; \mathrm{LV}: \mathrm{L}=1340, \mathrm{H}=729$.

\section{Differential diagnosis}

Bennelongia koendersae sp. nov. can be distinguished from all other species in the B. nimala lineage by the size and shape of the antero-ventral lapel on the RV, and from B. tirigie sp. nov. by the less pronounced anterior LV/RV overlap. Bennelongia koendersae sp. nov. can be distinguished from those species in the lineage where males are known (B. nimala, B. regina, B. tirigie sp. nov.) by the large and triangular second segment of the Rpp.

\section{Ecology and distribution}

The species is only known from its type locality, which is a small, ephemeral, turbid claypan.

\section{Remarks}

In a second sample from the 2006 KIES collecting expedition in Pilbara, a species close to $B$. koendersae sp. nov. was recognised with molecular methods only. This species (as Spec. 15 in Fig. 2) looked very much like $B$. koendersae sp. nov. and the only two specimens available were both screened in toto by molecular methods to establish conspecificity. Although these specimens cluster close to $B$. koendersae sp. nov. in the phylogenetic COI tree, they are considered to represent a second species (Fig. 2). As no further specimens are available, it could not be checked whether the species is cryptic or morphologically distinguishable from $B$. koendersae sp. nov. We thus leave this clade in open nomenclature.

\section{Locality of Spec. 15}

Ethel Creek claypan, east of Roy Hill Station, Pilbara, WA (sample KIES15). Approximate coordinates: $22^{\circ} 41^{\prime} 28^{\prime \prime}$ S, 119 $58^{\prime} 45^{\prime \prime}$ E. Specimens collected by the authors on 24 Apr. 2006.

\section{Bennelongia pinderi sp. nov. urn:1sid:zoobank.org:act:B2630A2B-D21E-4A5E-8B15-D5E0D9C13FAF} Figs $8 \mathrm{~A}-\mathrm{G}$

\begin{abstract}
Abbreviated description
Valves in inner view (Fig. 8A, C) relatively elongated, with rounded dorsal margin and greatest height situated slightly in front of the middle; ventral margin anteriorly without pronounced mandibular curve. LV (Fig. 8A) with antero-distal il running over halfway along the anterior valve margin, antero-proximal il running about $4 / 5$ way up along the anterior valve margin; posterior il tuberculate, but more delicately so than in the preceding three species, and running halfway up the posterior margin. RV (Fig. 8C) with antero-ventral lapel pronounced and rounded but with a smooth edge (Fig. 8F-G). Valves with external ornamentation mostly consisting of small tubercles, less pronounced than in the three preceding species (Fig. 8C-E).

Cp (Fig. 8C-E) with large LV/RV overlap, but less so than in the two preceding species. $\mathrm{CpD}$ and $\mathrm{CpV}$ with greatest width situated in the middle in females, anteriorly with strong and asymmetrical rostrum.
\end{abstract}


Soft parts as typical of the genus.

Male unknown.

\section{Etymology}

The species is named after Adrian M. Pinder (DPaW, Science and Conservation Division, Kensington, WA) in recognition of his substantial contribution to our knowledge about the taxonomy and ecology of freshwater invertebrates of Australia, especially freshwater Oligochaeta.

\section{Type material}

\section{Holotype}

ㅇ (WAMC55620), valves stored dry in a micropalaeontological slide and soft parts used for molecular screening.

\section{Paratypes}

Numerous females from the type locality, either stored as the holotype, as carapaces used for SEM or in alcohol (WAMC55621-55623, OC3378). See Table 1 for listing of specimens.

\section{Other material investigated}

Unnamed claypan near Murchison River, Murchison, WA (sample SIKE01). Approximate coordinates: $27^{\circ} 50^{\prime} 03^{\prime \prime} \mathrm{S}, 114^{\circ} 43^{\prime} 37^{\prime \prime}$ E. All material was collected by the authors on $5 \mathrm{Jul} .2011 . \mathrm{K} 25=28 \mu \mathrm{S} / \mathrm{cm}$, Temp $=8.3^{\circ} \mathrm{C}, \mathrm{pH}=5.8$.

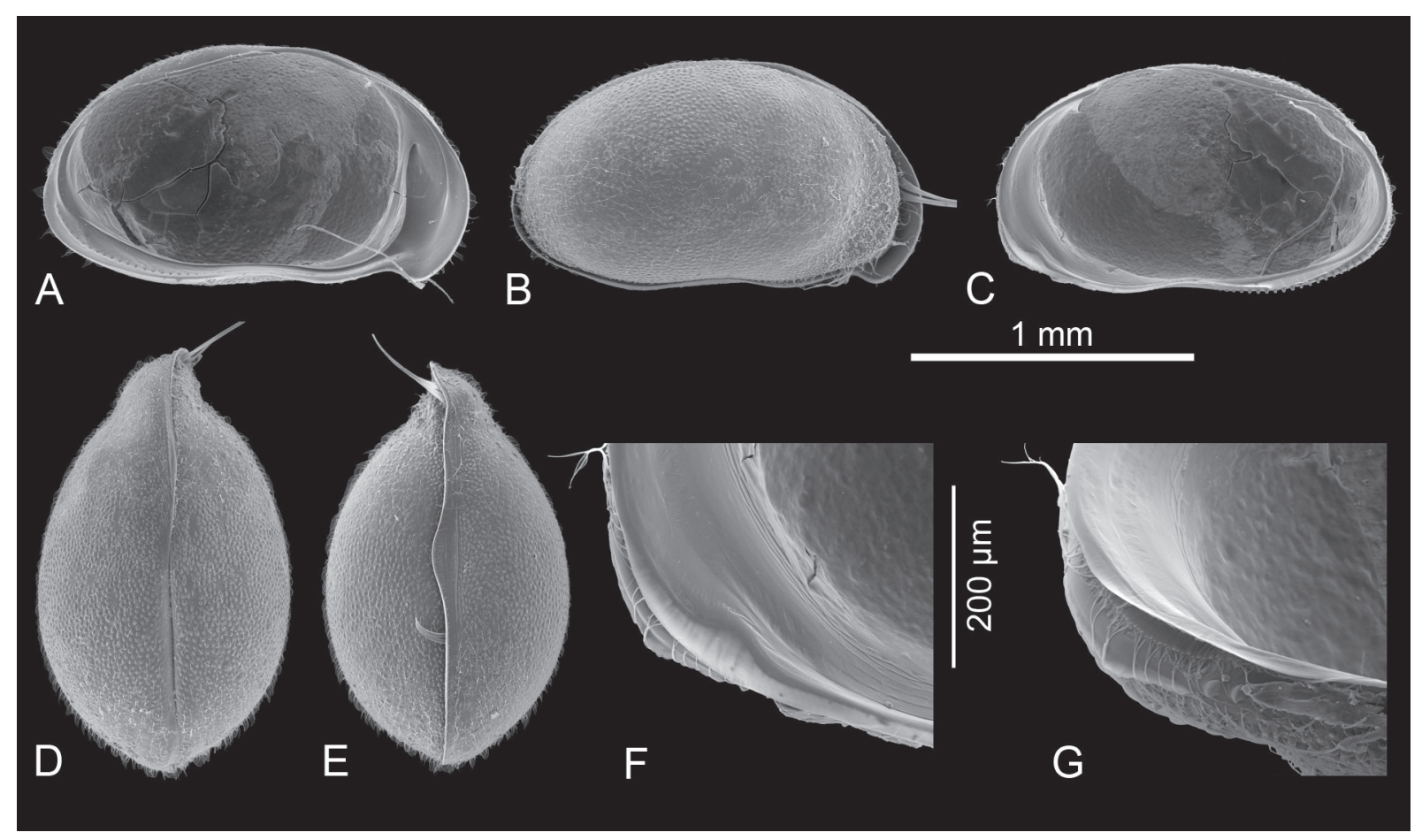

Fig. 8. Bennelongia pinderi sp. nov. (all $\circ$, all from type locality: unnamed claypan in Murchison/ Gascoyne, WA). A. LVi (holotype, WAMC55620). B. CpRL (WAMC55622). C. RVi (WAMC55620). D. CpD (WAMC55621). E. CpV (OC3378). F. RVi, detail anterior margin (WAMC55620). G. RVi, tilted, detail anterior margin (WAMC55620). Scale $=1 \mathrm{~mm}$ for A-E; $200 \mu \mathrm{m}$ for F-G. 
Roadside ditch on Euardy Station, Murchison, WA (sample SIKE05). Approximate coordinates: $27^{\circ} 35^{\prime} 31^{\prime \prime} \mathrm{S}, 114^{\circ} 41^{\prime} 43^{\prime \prime} \mathrm{E}$. All material was collected by the authors on 5 Jul. 2011. Several females (WAMC55624-55625). $\mathrm{K} 25=31 \mu \mathrm{S} / \mathrm{cm}, \mathrm{Temp}=14^{\circ} \mathrm{C}, \mathrm{pH}=6.7$.

\title{
Type locality
}

AUSTRALIA: Unnamed swamp, Coolcalalaya Station, Murchison, WA (samples CB06a, SIKE 3). Approximate coordinates: $27^{\circ} 31^{\prime} 22^{\prime \prime} \mathrm{S}, 15^{\circ} 04^{\prime} 23^{\prime \prime}$ E. All material collected by the authors on 5 Jul. 2011. $\mathrm{K} 25=33 \mu \mathrm{S} / \mathrm{cm}, \mathrm{Temp}=13.6^{\circ} \mathrm{C}, \mathrm{pH}=7.8$.

Measurements (all measurements in $\mu \mathrm{m}$ - see Table 1 for measurements of all specimens illustrated with SEM)

Holotype + (WAMC55620): RV: $\mathrm{L}=1395, \mathrm{H}=810 ; \mathrm{LV}: \mathrm{L}=1507, \mathrm{H}=840$.

\section{Differential diagnosis}

Bennelongia pinderi sp. nov. is most closely related to B. koendersae sp. nov., but is ca. $15-20 \%$ larger, has a less pronounced valve ornamentation and has a less-developed antero-ventral lapel with a smooth edge on the RV rather than serrated as in B. koendersae sp. nov.

\section{Ecology and distribution}

Bennelongia pinderi sp. nov. has thus far been found in three seasonal or ephemeral water bodies in the Murchison region of WA.

$$
\begin{gathered}
\text { Bennelongia muggon sp. nov. } \\
\text { urn:1sid:zoobank.org:act:38D3B6B7-30B5-4F70-AE39-A46A3213719C }
\end{gathered}
$$

Fig. $9 \mathrm{~A}-\mathrm{N}$

Bennelongia cf. nimala nov. sp. - De Deckker \& Martens 2013: 6-7, figs 2-10.

\begin{abstract}
Abbreviated description
Valves in inner view (Fig. 9A,C) relatively high, with rounded dorsal margin and greatest height situated well in front of the middle; ventral margin anteriorly with slight mandibular curve. LV (Fig. 9A) with antero-distal il running over halfway along the anterior valve margin, antero-proximal il running less than halfway up along the anterior valve margin; posterior il running more than halfway up the posterior margin, but mostly smooth, not tuberculate. RV (Fig. 9C) with antero-ventral lapel pronounced and droplet-shaped, with delicately serrated edge (Fig. 9C, H-I, K-N). Valves with external ornamentation mostly consisting of small tubercles (Fig. 9B, D-H).
\end{abstract}

Cp (Fig. 9C-G) with strong LV/RV overlap, almost as large as in B. tirigie sp. nov. CpD and CpVwith greatest width situated in the middle in females, anteriorly with less pronounced, asymmetrical rostrum.

Soft parts as typical of the genus.

Male unknown.

\section{Etymology}

The species is named after its type locality, a large lake on Muggon Station, Murchison, WA. 

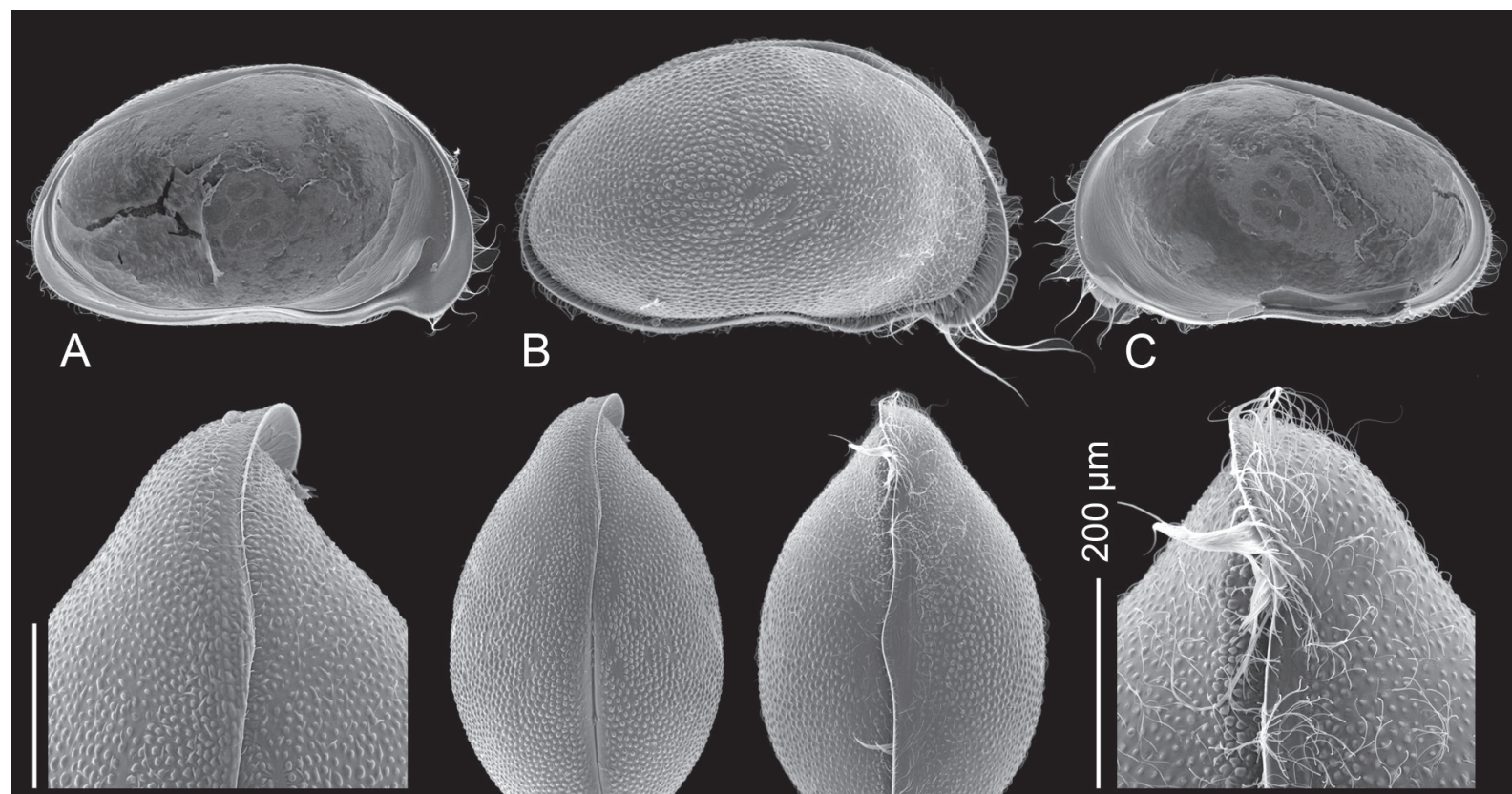

D
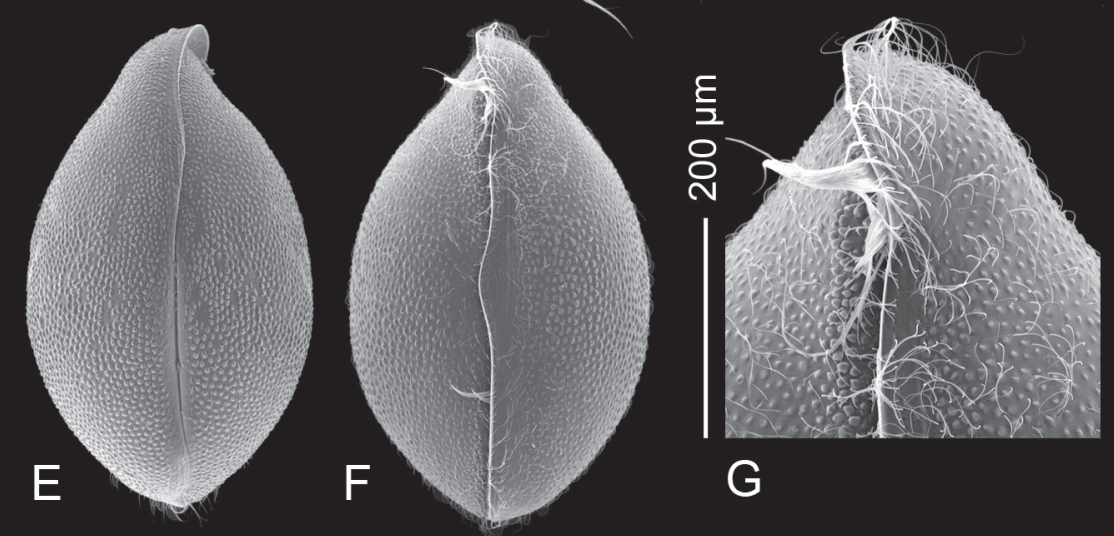

G
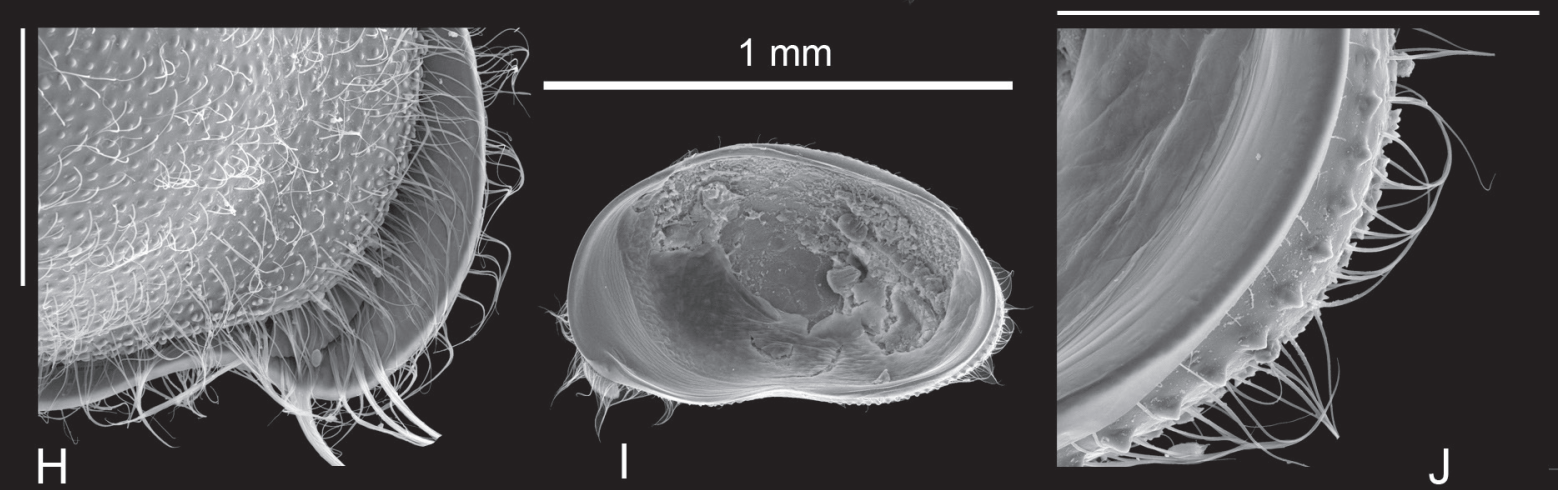

$\mathrm{H}$
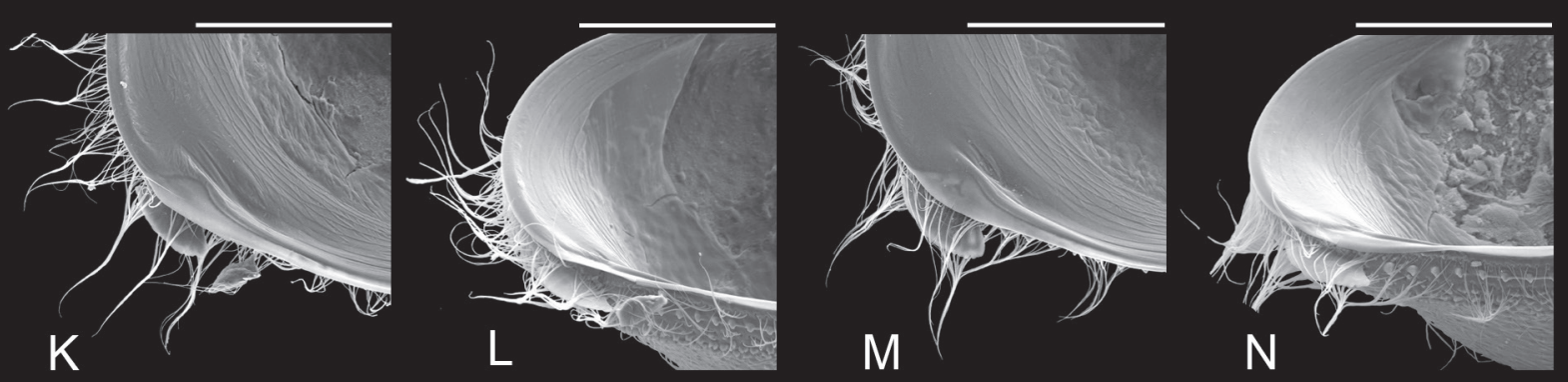

Fig. 9. Bennelongia muggon sp. nov. (all + , from type locality: Lake Muggon, Murchison/Gascoyne, WA). A. LVi (holotype, WAMC55632). B. CpRL (WAMC55635). C. RVi (WAMC55632). D. CpD, detail anterior margin (WAMC55634). E. CpD (WAMC55634). F. CpV (WAMC55636). G. CpV, detail anterior margin (WAMC55636). H. CpRL, detail anterior margin (WAMC55635). I. RVi (WAMC55633). J. RVi, detail posterior margin (WAMC55633). K. RVi, detail anterior margin (WAMC55632). L. RVi, tilted, detail anterior margin (WAMC55632). M. RVi, detail anterior margin (WAMC55633). N. RVi, tilted, detail anterior margin (WAMC55633). Scales $=1 \mathrm{~mm}$ for A-C, E-F, I; $200 \mu \mathrm{m}$ for D, G-H, J-N. 
MARTENS K., HALSE S. \& SCHÖN I., Bennelongia lineages in Western Australia

\title{
Type material
}

\section{Holotype}

ㅇ (WAMC55632), valves stored dry in a micropalaeontological slide, with soft parts used for molecular screening.

\section{Paratypes}

Numerous females from the type locality, either stored as the holotype, as carapaces used for SEM or in alcohol (WAMC55633-55645, OC3381-3383). See Table 1 for listing of specimens.

\section{Other material investigated}

Unnamed canegrass pan on Boolathana Station, Gascoyne, WA (sample SIKE 12). Approximate coordinates: $24^{\circ} 44^{\prime} 41^{\prime \prime} \mathrm{S}, 113^{\circ} 43^{\prime} 22^{\prime \prime}$ E. All material collected by the authors on 6 Jul. 2011. K25 = $1020 \mu \mathrm{S} / \mathrm{cm}, \mathrm{pH}=8.7, \mathrm{Temp}=16.9^{\circ} \mathrm{C}$.

Dam at Solomon's Well, Victoria Plains, WA (sample DJC/04). Approximate coordinates: 31 ${ }^{\circ} 11^{\prime} 59^{\prime \prime}$ S, $116^{\circ} 21^{\prime} 47.7^{\prime \prime}$ E. All material collected by David J. Cale (DPaW, Kensington) on 9 Sep. 2011. K25 = 120 $\mu \mathrm{S} / \mathrm{cm}, \mathrm{pH}=6.8, \mathrm{Temp}=14.4^{\circ} \mathrm{C}$.

Petrudor Dam, Wheatbelt, WA (sample DJC/15). Approximate coordinates: $30^{\circ} 25^{\prime} 19^{\prime \prime}$ S, $116^{\circ} 57^{\prime} 40^{\prime \prime}$ E. All material collected by David J. Cale (DPaW, Kensington) on 11 Sep. 2011. K25 = $162 \mu \mathrm{S} / \mathrm{cm}, \mathrm{pH}$ $=7.85$, Temp $=22.0^{\circ} \mathrm{c}$.

\section{Type locality}

AUSTRALIA: Unnamed large lake at Muggon Station, Murchison, WA (sample SIKE 20). Approximate coordinates: $26^{\circ} 44^{\prime} 15^{\prime \prime} \mathrm{S}, 115^{\circ} 29^{\prime} 59^{\prime \prime}$ E. All material collected by the authors on 8 Jul. 2011. K25 = 475 $\mu \mathrm{S} / \mathrm{cm}, \mathrm{pH}=8.9, \mathrm{Temp}=13.4^{\circ} \mathrm{C}$.

Measurements (all measurements in $\mu \mathrm{m}$ - see Table 1 for measurements of all specimens illustrated with SEM)

Holotype + (WAMC55632): RV: $\mathrm{L}=1015, \mathrm{H}=603$; LV: $\mathrm{L}=1078, \mathrm{H}=638$.

\section{Differential diagnosis}

This is the smallest of all species described in the present paper. Bennelongia muggon sp. nov. can further be distinguished from other members of the $B$. nimala lineage by the size and shape of the anteroventral lapel on the RV, the smooth posterior il and the short anterior inner il in the $\mathrm{LV}$.

\section{Ecology and distribution}

This is one of the more common species in this lineage, as it has been found in several freshwater dams and pans from the Gascoyne region south to the Wheatbelt, WA. It occurs in fresh turbid water.

Bennelongia shieli sp. nov. urn:1sid:zoobank.org:act:3739DA56-41CC-47FA-93A6-44BBFBFFB52E

Fig. 10A-M

\begin{abstract}
Abbreviated description
Valves in inner view (Fig. 10A-B, G, I) relatively high, with almost straight dorsal margin, parallel to ventral margin in RV, sloping caudally in LV; greatest height situated well in front of the middle; ventral margin anteriorly with slight mandibular curve. LV (Fig. 10A, G) with antero-distal il running almost along the entire anterior valve margin, almost connecting with ventral inner list; antero-proximal
\end{abstract}


il reaching halfway up along the anterior valve margin; posterior il running more than halfway up the posterior margin, tuberculate for most of its length. LV with 2-3 spines halfway up the posterior margin (Fig. 10A, D, G). RV (Fig. 10B, I) with antero-ventral lapel elongated and slightly serrate, with a large tooth (Fig. 10B, I, K-M). Valves with external ornamentation mostly consisting of small tubercles (Fig. 10C-F, H). (Remark: one specimen showed a larger tooth on the antero-ventral lapel on the RV; this may be an aberrant individual).

Cp (Fig. 10E-F, H) with strong LV/RV overlap, but less so than in B. tirigie sp. nov., B. koendersae sp. nov. and B. muggon sp. nov. CpRL with LV forming an antero-dorsal hump over RV. CpD and CpV with greatest width situated slightly behind the middle in females, anteriorly with strongly pronounced, asymmetrical rostrum, dorsally set with parallel rows of tubercles, as in B. nimala.

Soft parts as typical of the genus.

Male unknown.

\section{Etymology}

The species is named after Dr Russell Shiel (University of Adelaide, Adelaide) in recognition of his substantial contribution to the taxonomy and ecology of freshwater invertebrates, especially rotifers and cladocerans, of Australia.

\section{Type material}

\section{Holotype}

o (WAMC55626), with soft parts dissected in a sealed slide and valves stored dry in a micropalaeontological slide.

\section{Paratypes}

Numerous females from the type locality, either stored as the holotype, as carapaces used for SEM or in alcohol (WAMC55627-55631, OC3379-3380). See Table 1 for listing of specimens.

\section{Type locality}

AUSTRALIA: Munreemya Billabong, Pilbara, WA (sample PSW036 = OSTR133). Approximate coordinates: $20^{\circ} 40^{\prime} 12^{\prime}$ S, $120^{\circ} 13^{\prime} 33.6$ " E. Material collected by Adrian Pinder and Harley Barron on 19 May 2004. $\mathrm{K} 25=194 \mu \mathrm{S} / \mathrm{cm}, \mathrm{pH}=8.54, \mathrm{Temp}=23^{\circ} \mathrm{C}$.

Measurements (all measurements in $\mu \mathrm{m}$ - see Table 1 for measurements of all specimens illustrated with SEM)

Holotype + (WAMC55626): RV: $\mathrm{L}=1380, \mathrm{H}=807$; LV: $\mathrm{L}=1467, \mathrm{H}=888$.

\section{Differential diagnosis}

In shape and valve ornamentation, the species differs from all others described here except $B$. nimala, which it resembles. However, $B$. shieli sp. nov. has a much wider anterior LV/RV overlap than $B$. nimala and is also about $10 \%$ smaller. In $B$. nimala, the anterodorsal inner list almost connects with the ventral list and clearly overlaps with the anteroventral inner list. In addition, the antero-ventral lapel on the RV is also different in both species.

\section{Ecology and distribution}

The species is known from its type locality only, a freshwater semi-permanent billabong in the northern Pilbara. 


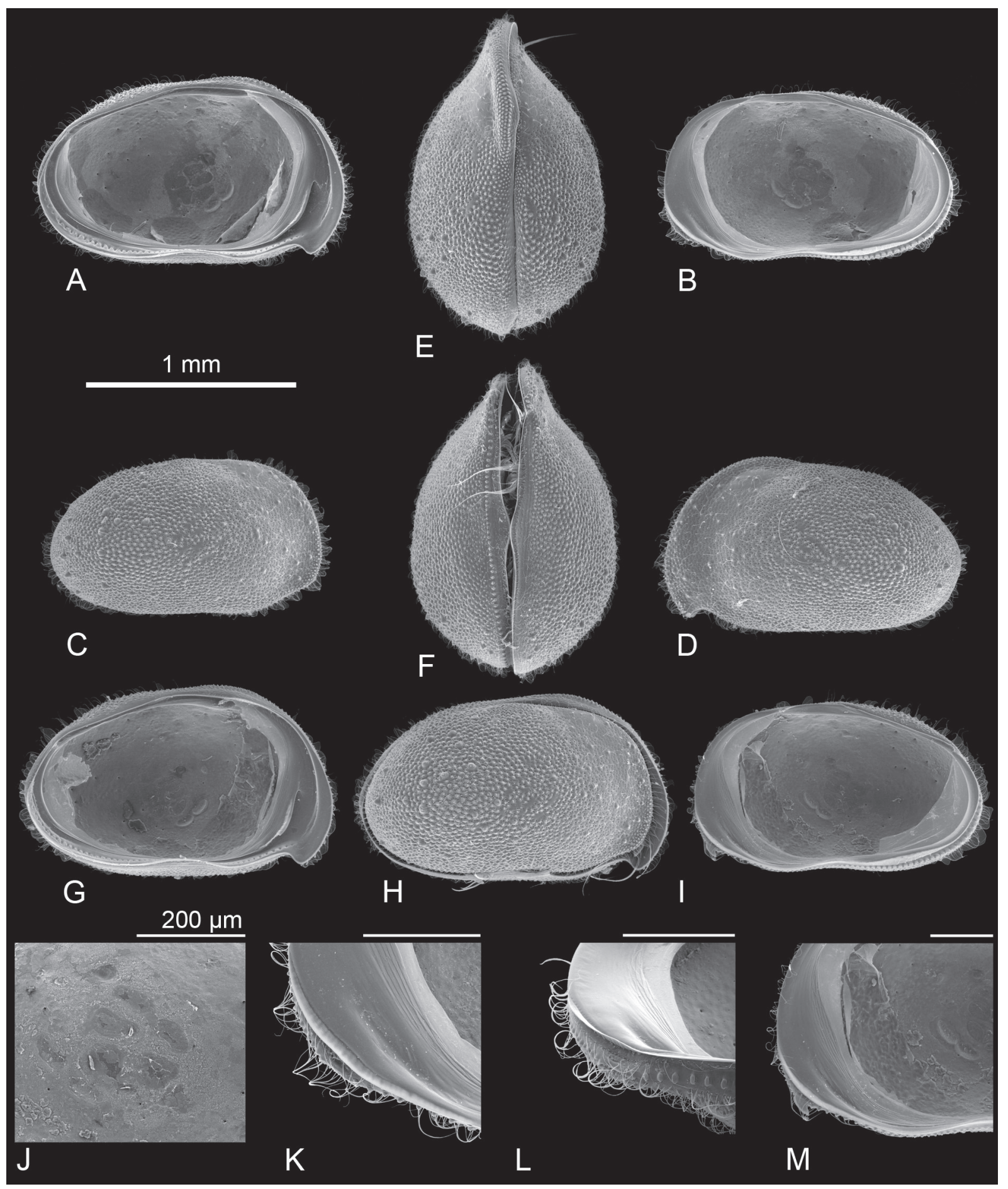

Fig. 10. Bennelongia shieli sp. nov. (all $\odot$, all from type locality: Munreemya Billabong, Pilbara, WA). A. LVi (holotype, WAMC55626). B. RVi (WAMC55626). C. RVe (WAMC55627). D. LVe WAMC55627). E. CpD (WAMC55628). F. CpV (WAMC55629). G. LVi (WAMC55630). H. CpRL (OC3379). I. RVi (WAMC55630). J. RVi, detail central muscle scars (WAMC55627). K. RVi, detail anterior margin (WAMC55626). L. RVi, tilted, detail anterior margin (WAMC55626). M. RVi, detail anterior margin (WAMC55630, aberrant specimen). Scales $=1 \mathrm{~mm}$ for A-I; $200 \mu \mathrm{m}$ for J-M. 
Bennelongia triangulata lineage

\title{
Diagnosis of the $B$. triangulata lineage
}

Large $(\mathrm{L}>2 \mathrm{~mm})$ and triangular species, with ventral margins nearly smooth, without an antero-ventral beak on the LV. Anterior LV/RV overlap moderate. $\mathrm{CpD}$ and $\mathrm{CpV}$ without pronounced anterior rostrum. Last 3 juvenile stages with fully flat ventral side, not so in adults.

\section{Remarks}

De Deckker \& Martens (2013) described the morphology of the last 3 instar juveniles of $B$. triangulata sp. nov. (as $B$. sp. 414) and found that they have, unlike juveniles of any other Benelongia species, a fully flat ventral side. This feature is an important part of the diagnosis of the lineage.

This lineage and species are atypical for Bennelongia, in that some of the obvious features, such as the long beak in the B. australis lineage or the large LV/RV overlap in the B. nimala lineage, are missing. Nevertheless, the structure of the valve margins of both valves is most similar to the other species in the genus, and also the soft parts, apart from being slightly more elongated, show no structural differences. We thus maintain this species in Bennelongia.

\section{Bennelongia triangulata sp. nov. urn:1sid:zoobank.org:act:2EE84F9D-40BD-4866-9E42-5B6815D95E1A}

Figs $11 \mathrm{~A}-\mathrm{M}, 12 \mathrm{~A}-\mathrm{M}, 13 \mathrm{~A}-\mathrm{G}$

Bennelongia sp. nov. 414 - Halse et al. 2000: table 4, appendix 4.

Bennelongia $\mathrm{n}$. sp. 414 - Pinder et al. 2010: appendix 2.

Bennelongia sp. 414 nov. sp. - De Deckker \& Martens 2013: 7-8, figs 11-12.

\begin{abstract}
Abbreviated description
Valves in inner view (Figs 11A, C, H, J; 12A, C, H, J) subtriangular, with greatest height situated either in the middle or just before the middle; ventral margin almost straight, with weak mandibular curve. LV (Figs 11A, H; 12A, H) with antero-distal il running only halfway along the anterior valve margin, antero-proximal il running slightly beyond halfway up along the valve margin, this list dorsally strongly S-shaped; posterior il smooth, not tuberculate, and running only along ventral margin. RV (Figs 11C, $\mathrm{J} ; 12 \mathrm{C}, \mathrm{J}$ ) with antero-ventral lapel a very narrow ridge, but valve margin protruding beyond selvage as in the Bennelongia pinpi lineage (Figs 11C, I-M; 12C-D, G, I-J, L-M). Valves with delicate external ornamentation, consisting of small tubercles (Figs 11D, G, L; 12G, I, M).
\end{abstract}

Cp (Fig. 11B, D-G, L) with moderate LV/RV overlap. $\mathrm{CpD}$ and $\mathrm{CpV}$ with greatest width situated in the middle in both males and females (Figs 11E-F; 12E-F), without anterior rostrum.

Soft parts as typical of the genus, but generally more elongated than in the other species of Bennelongia. Hemipenes (Fig. 13A, E) symmetrical, edge of ms almost straight, ls with ventral extremity strongly pointed. Lpp (Fig. 13B, F) with distal segment narrow, tapering towards the point and rather long (the specimen in Fig. 13C is an exception). Rpp (Fig. 13D, G) with distal segment narrowly subtriangular, with apical margin straight, sensory organs on first segment unequal, one long, one short.

\section{Etymology}

The species is named after its most striking character, the triangular shape of the valves in lateral view. 


\section{MARTENS K., HALSE S. \& SCHÖN I., Bennelongia lineages in Western Australia}

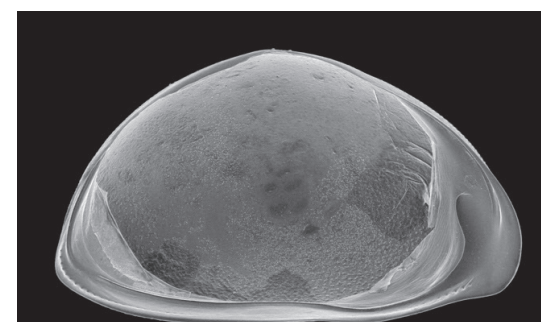

A

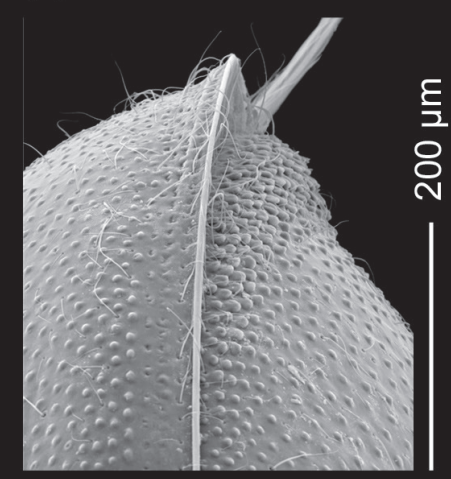

D

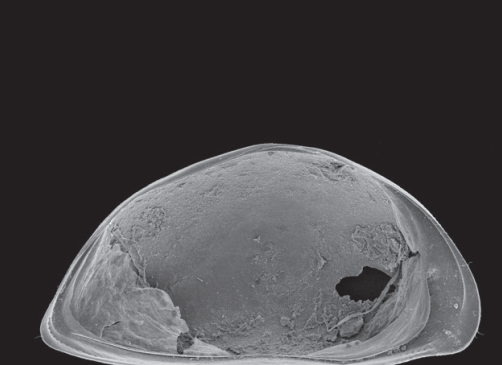

$\mathrm{H}$

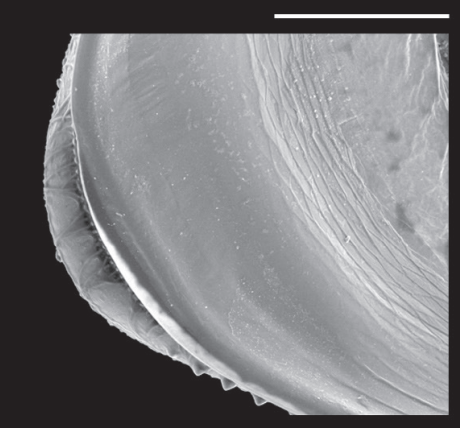

$\mathrm{K}$

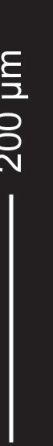

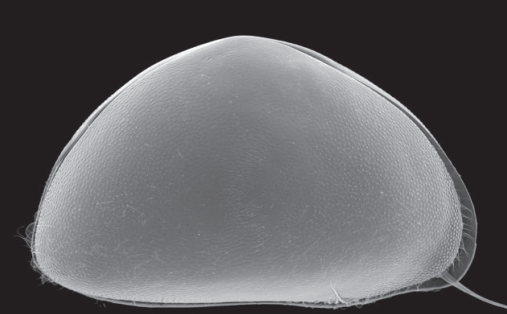

B

E
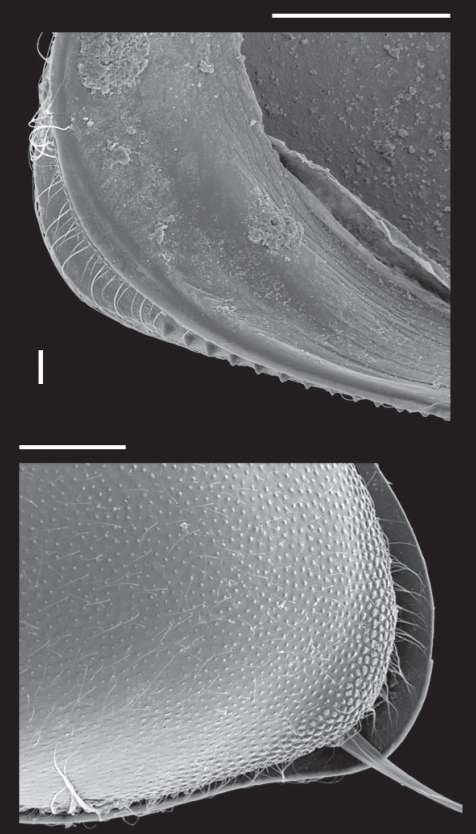

L

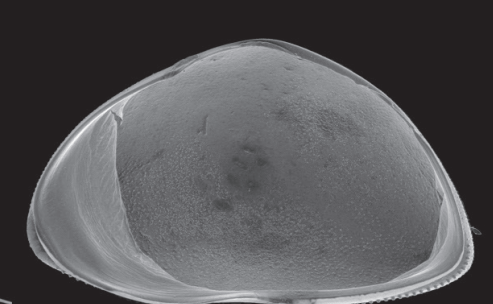

C

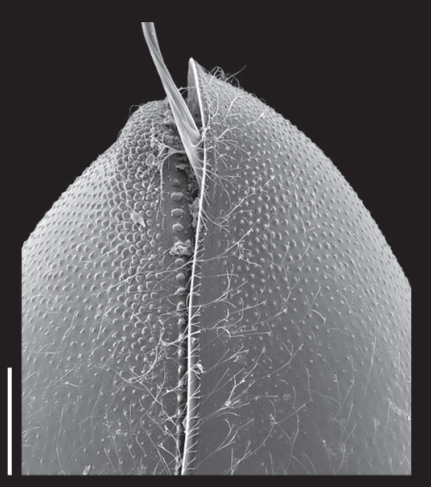

G

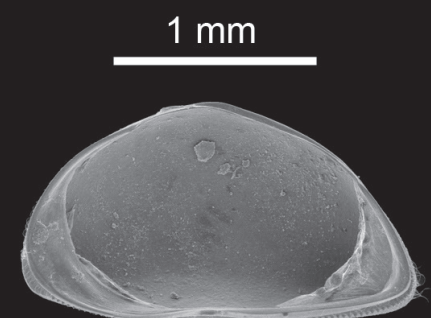

$\mathrm{J}$

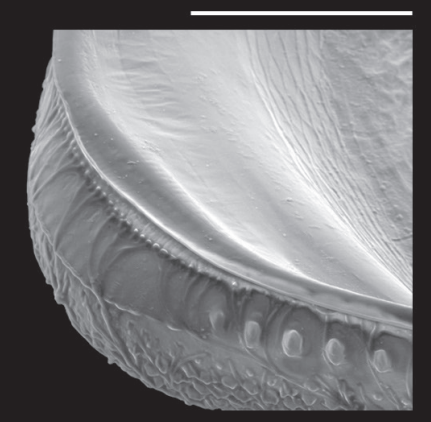

$\mathrm{M}$

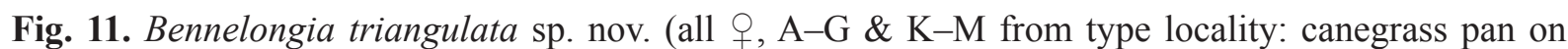
Wooramel Station, Murchison/Gascoyne, WA; H-J from CB54, Boolathana Station, Carnarvon Basin, WA). A. LVi (allotype, WAMC55565). B. CpRL (OC3368). C. RVi (WAMC55565). D. CpD, detail anterior margin (WAMC55569). E. CpD (WAMC55569). F. CpV (WAMC55570). G. CpV, detail anterior margin (WAMC55570). H. LVi (OC3370). I. LVi, detail posterior margin (OC3370). J. RVi (OC3370). K. RVi, detail anterior margin (WAMC55565). L. CpRL, detail anterior margin (OC3368). M. RVi, tilted, detail anterior margin (WAMC55565). Scales $=1 \mathrm{~mm}$ for A-C, E-F, H, J; $200 \mu \mathrm{m}$ for D, G, I, K-M. 


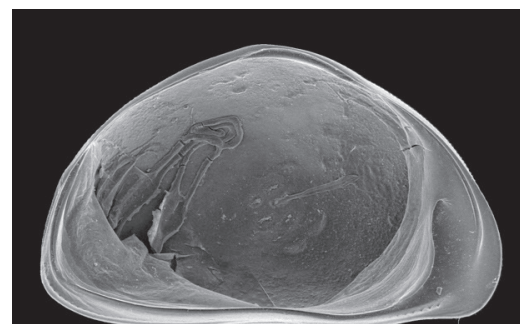

A

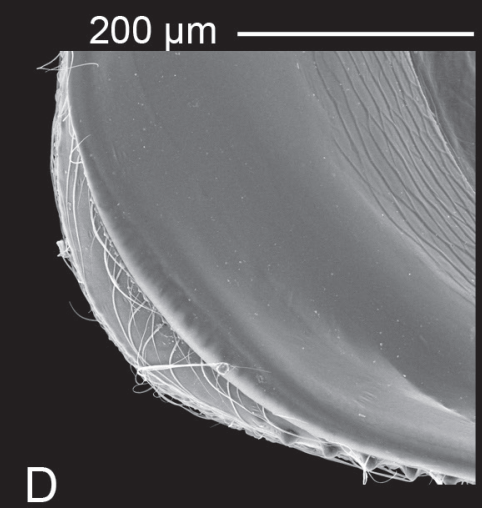

$1 \mathrm{~mm}$

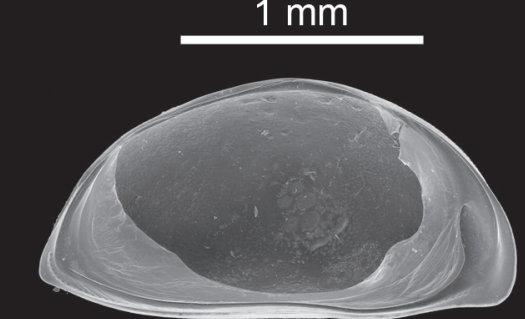

$\mathrm{H}$

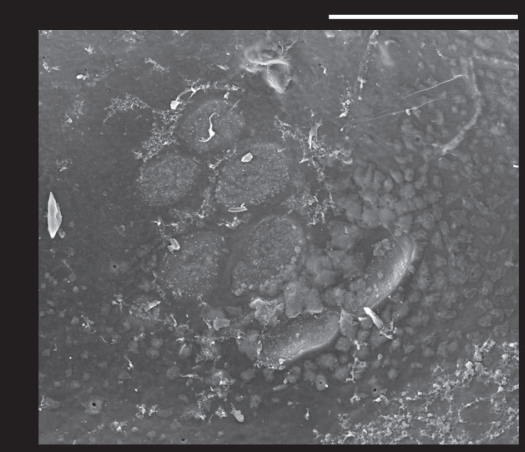

K

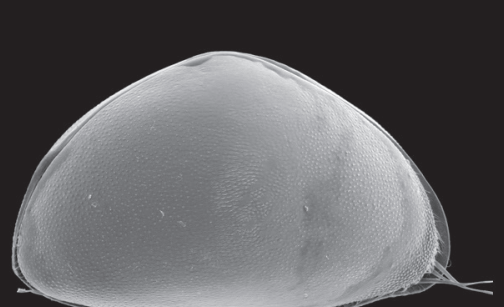

B
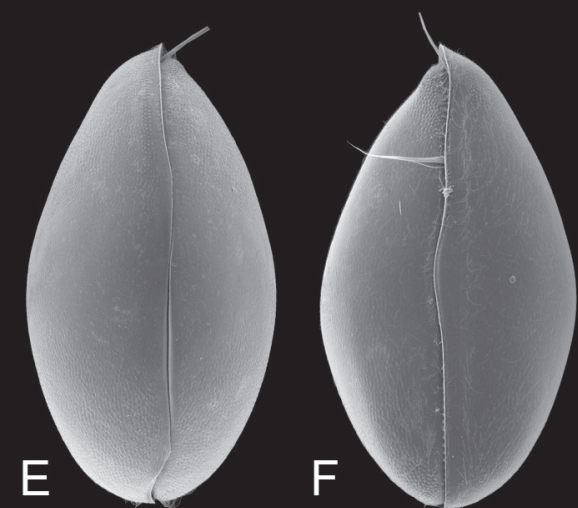

C

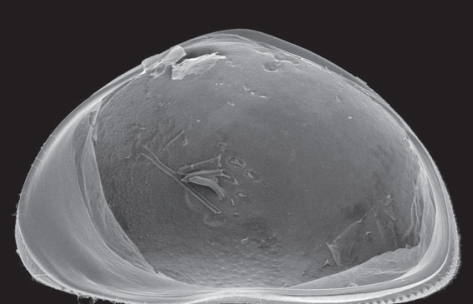

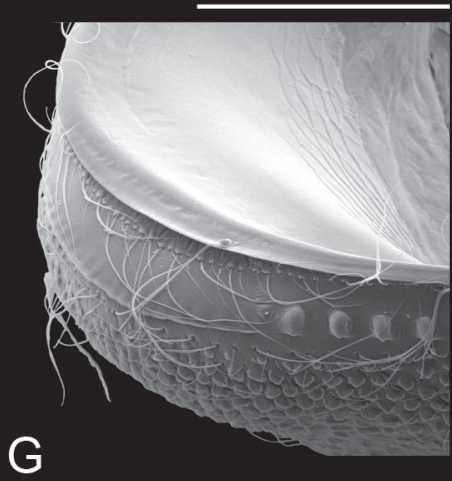
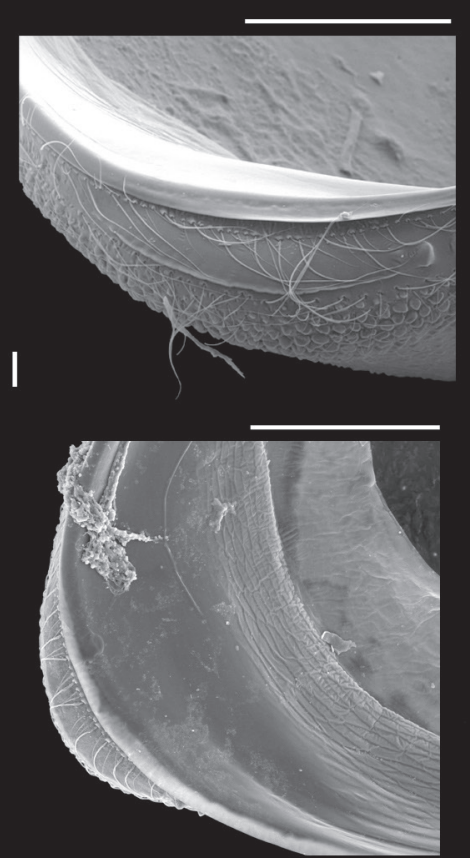

L

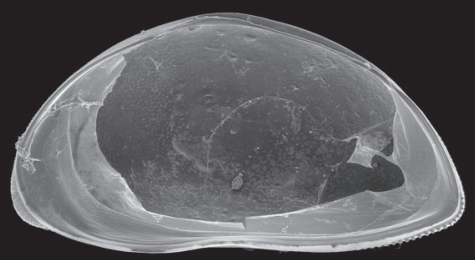

J

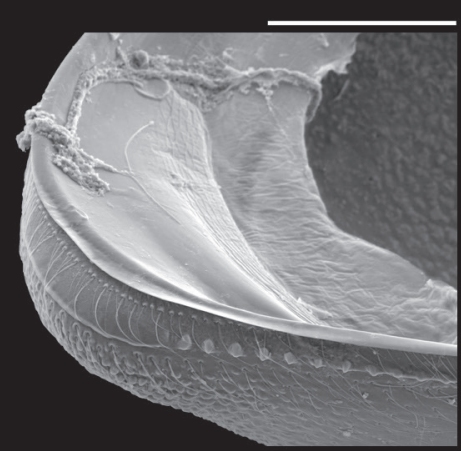

M

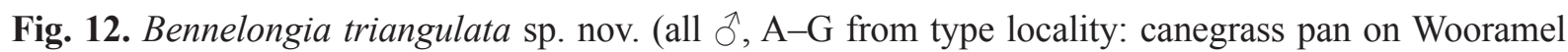
Station, Murchison/Gascoyne, WA; H-M from CB54, Boolathana Station, Carnarvon Basin, WA). A. LVi (holotype, WAMC55564). B. CpRL (OC3369). C. RVi (WAMC55564). D. RVi, detail anterior margin (WAMC55564). E. CpD (WAMC55571). F. CpV (WAMC55572). G. RVi, tilted, detail anterior margin (WAMC55564). H. LVi (WAMC55574). I. RVi, tilted, detail anterior margin (WAMC55564). J. RVi (WAMC55574). K. LVi, detail central muscle scars (WAMC55574). L. RVi, detail anterior margin (WAMC55574). M. RVi, tilted, detail anterior margin (WAMC55574). Scale = $1 \mathrm{~mm}$ for A-C, E-F, H, J; $200 \mu \mathrm{m}$ for D, G, I, K-M. 


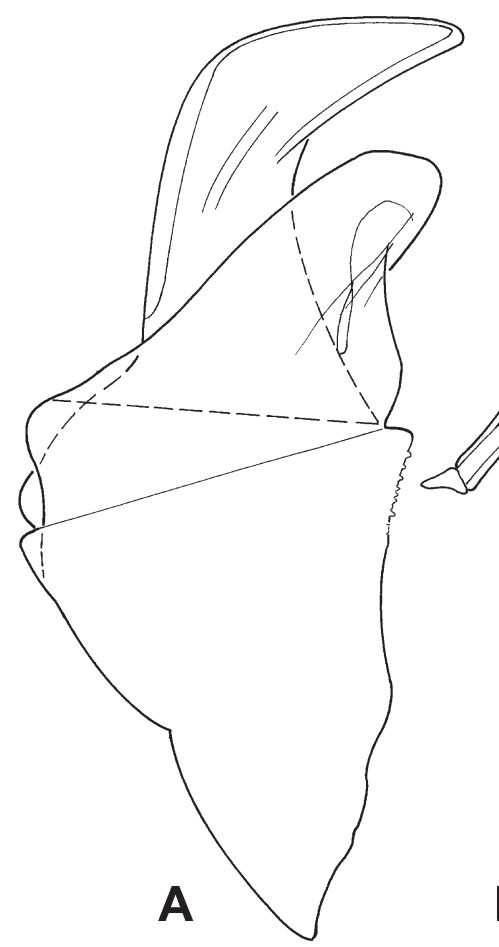

B
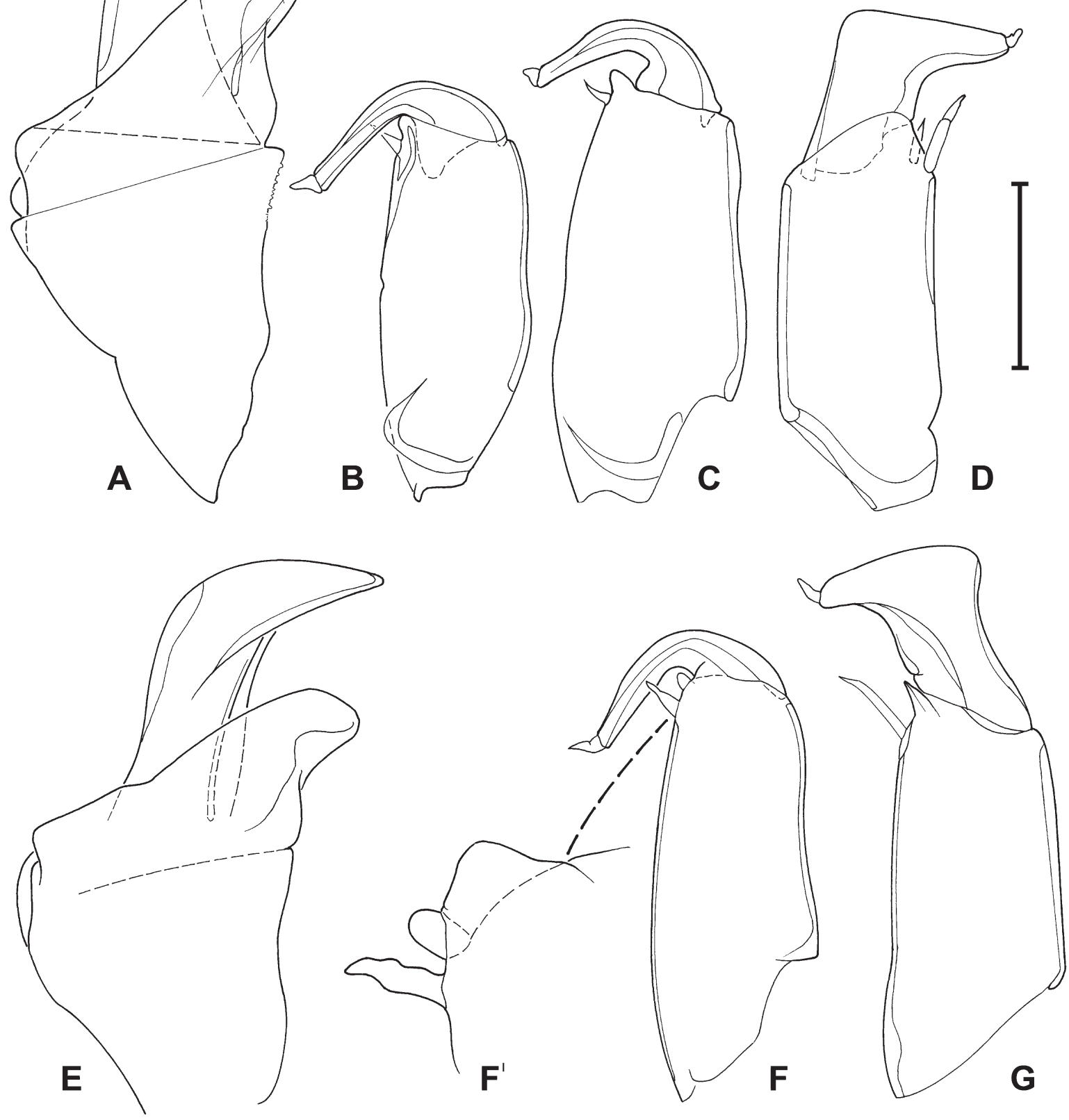

Fig. 13. Bennelongia triangulata sp. nov. (all ô, A-D from CB75a, Cattle Camp Pan, Gascoyne, WA; E-G holotype (WAMC55564): cane grass pan on Wooramel Station, Murchison/Gascoyne, WA). A. Outline of hemipenis (WAMC55584). B. Lpp (WAMC55584). C. Lpp (WAMC55575). D. Rpp (WAMC55584). E. Outline of hemipenis. F. Lpp. F'. Lpp, detail of distal part of first segment. G. Rpp. Scale $=156 \mu \mathrm{m}$ for A, E; $73 \mu \mathrm{m}$ for B-D, F-G. 


\section{Type material}

\section{Holotype}

o (WAMC55564), with soft parts dissected in a sealed slide and valves stored dry in a micropalaeontological slide.

\section{Allotype}

o (WAMC55565), with valves stored dry in a micropalaeontological slide and soft parts used for molecular screening.

\section{Paratypes}

Numerous $\hat{O} \sigma^{\lambda}$ and $q+q$ from the type locality, either dissected and stored as the holotype, as carapaces used for SEM or in alcohol (WAMC55566-55573, OC3367-3369). See Table 1 for listing of specimens.

\section{Other material investigated}

Unnamed claypan, Gascoyne, WA (sample SIKE11). Approximate coordinates: 244' $49^{\prime \prime}$ S, $114^{\circ} 15^{\prime} 42^{\prime \prime}$ E. All material collected by the authors on 6 Jul. 2011. Several males and females (specimens WAMC55576-55577). $\mathrm{K} 25=434 \mu \mathrm{S} / \mathrm{cm}$, Temp $=15.4^{\circ} \mathrm{C}, \mathrm{pH}=7.6$.

Unnamed claypan, Muggon Station, Murchison, WA (sample SIKE21). Approximate coordinates: $26^{\circ} 46^{\prime} 54^{\prime \prime} \mathrm{S}, 115^{\circ} 40^{\prime} 53^{\prime \prime}$ E. All material collected by the authors on 8 Jul. 2011. Several males and females (specimens WAMC55578-55583). $\mathrm{K} 25=154 \mu \mathrm{S} / \mathrm{cm}, \mathrm{Temp}=13.3^{\circ} \mathrm{C}, \mathrm{pH}=8.0$.

Homestead dam, Boolathana Station, Gascoyne, WA (sample ESKI/01). Approximate coordinates: $24^{\circ} 39^{\prime} 15^{\prime \prime}$ S, $113^{\circ} 41^{\prime} 37^{\prime \prime}$ E. All material collected by the authors on 5 Apr. 2013. Several females (specimens WAMC55584).

Unnamed canegrass pan, Wooramel Stn, Gascoyne, WA (sample CB35a). Approximate coordinates: $25^{\circ} 40^{\prime} 52^{\prime}$ S, $114^{\circ} 13^{\prime} 14^{\prime \prime}$ E. Material collected by Stuart Halse on 24 Aug. 1994 (specimen OS256).

Near Cardabia Swamp, Gascoyne, WA (sample CB54). Approximate coordinates: 243'ㅇ' S, 11345’35” E. Material collected by Stuart Halse on 18 Mar. 1995 (specimen OC3370).

Unnamed claypan, Doorawarrah Stn, Gascoyne, WA (sample CB58b). Approximate coordinates:

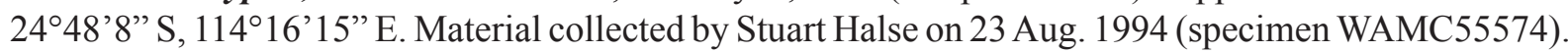

Boolan Pool, Gascoyne, WA (sample CB73). Approximate coordinates: 2428’38” S, 11340’36” E. All material collected by Stuart Halse on 18 Aug. 1994 (specimens OS121, OS391).

Cattle Camp Pan, Gascoyne, WA (sample CB75a). Approximate coordinates: 242'ㄹ' S, $114^{\circ} 13^{\prime 2} 27^{\prime \prime}$ E. Material collected by Stuart Halse on 19 Aug. 1994 (specimen WAMC55575).

Nicabay Flats, Gascoyne, WA. Approximate coordinates: $24^{\circ} 52^{\prime} 7^{\prime \prime}$ S, $113^{\circ} 43^{\prime} 3^{\prime \prime}$ E. Material collected by Stuart Halse on 15 Aug. 1995 (specimen OS258).

\section{Type locality}

AUSTRALIA: Unnamed canegrass pan on Wooramel Station, Gascoyne, WA (samples CB35a and SIKE07). Approximate coordinates: $25^{\circ} 40^{\prime} 53^{\prime \prime} \mathrm{S}, 114^{\circ} 13^{\prime} 17^{\prime \prime}$ E. All material collected by the authors on 5 Jul. 2011. $\mathrm{K} 25=307 \mu \mathrm{S} / \mathrm{cm}, \mathrm{Temp}=15.5^{\circ} \mathrm{C}, \mathrm{pH}=7.4$. 
Measurements (all measurements in $\mu \mathrm{m}$ - see Table 1 for measurements of all specimens illustrated with SEM)

Holotype $\widehat{\partial}$ (WAMC55564): RV: $\mathrm{L}=1850, \mathrm{H}=1158$; $\mathrm{LV}: \mathrm{L}=1923, \mathrm{H}=1188$.

Allotype + (WAMC55565): RV: $\mathrm{L}=2192, \mathrm{H}=1308$; LV: $\mathrm{L}=2286, \mathrm{H}=1350$.

\section{Differential diagnosis}

This species is unlike any other species in the genus, because of the features cited in the diagnosis to the $B$. triangulata lineage, especially the large size, triangular shape and lack of an antero-ventral beak on the LV.

\section{Remark}

The species comes in two forms, one with valves high (Figs $11 \mathrm{~A}-\mathrm{C} ; 12 \mathrm{~A}-\mathrm{C}$ ) and one with valves more elongated (Figs $11 \mathrm{H}, \mathrm{J} ; 12 \mathrm{H}, \mathrm{J}$ ). In the soft parts, both forms are almost identical, with the exception of the shape of the second segment of the Rpp. In the high form, this segment is subtriangular, with both dorsal and distal margins straight (Fig. 13D). In the more elongated form, this segment has a straight distal, but more sinuous dorsal margin (Fig. 13G).

\section{Morphology, ecology and distribution}

Bennelongia triangulata sp. nov. is common in the Murchison region north to the southern Pilbara region of WA and occurs in turbid claypans. As outlined above, the valve shape can be quite different (either rather high, or quite elongated), and originally it was thought that these two forms were either seasonally determined or constituted two species.

New sampling and screening of older collections showed that both forms occur in both summer and winter. Laboratory cultures reared at different temperatures, day length etc. may show which, if any, aspects of the environment may affect valve shape in this species. Males with different valve shape have slightly different morphologies in the Rpp, but as this could be part of a normal range of variability, its occurrence should be checked on longer series of dissections. Bennelongia timmsi Martens et al., 2013 also showed significant variability in the shape of the Rpp (Martens et al. 2013).

Sadly, all specimens with elongated valves originated from old collections, on which no molecular work could be done. In spite of several attempts, we have not been able to collect fresh material of the elongated form. Future work will have to examine whether genetic data suggest that the two forms are different species. For the moment we retain both forms as being conspecific.

\section{Discussion}

\section{B. nimala lineage}

The Bennelongia nimala lineage presently consists of seven species, which are united by the presence of heavily calcified and heavily ornamented adult valves. Valve ornamentation consists of large pustules, spines and short and stiff setae. It is in the $B$. nimala lineage that the heavily ornamented valves of the juveniles of the last instars of most Bennelongia species, as described by De Deckker \& Martens (2013), are strongly retained in the adults. With regard to these features, the species in this lineage show the most retarded heterochronic development. However, in other features, for example the strongly developed anterior LV/RV overlap, the species show the most derived valve characters.

Two species of the B. nimala lineage (B. pinderi sp. nov. and B. muggon sp. nov.) have an eyelet in the anteroventral part of the RV, much as in the B. barangaroo lineage (see Martens et al. 2013), indicating that these lineages are more closely related to one another than the valve morphology might indicate at first glance. Species of the B. barangaroo lineage have valves that are much smoother and only weakly pitted, although they can in some species be quite hirsute. As is usual in ostracods (Tsukagoshi 1988; 
Martens et al. 2004), morphology of the different lineages of Bennelongia shows a mixture of different heterochronic processes.

As in the other lineages of Bennelongia (Martens et al. 2012, 2013; Shearn et al. 2012), the anteroventral lapel on the RV proved to be a species-specific feature, allowing distinction between species in the lineage and genus. In the $B$. nimala lineage, the lapel is most strongly developed in $B$. nimala, where it has the appearance of a toothed comb, and weakest in $B$. pinderi sp. nov., where it is a small smooth ridge. Bennelongia muggon sp. nov. has a pronounced triangular lapel, reminiscent of some of the species in the B. barangaroo lineage (B. timmsi, B. scanloni).

The B. nimala lineage occurs in the NT (the nominal B. nimala) as well as in the western part of WA, between Pilbara and Perth. Additional information about the frequency of occurrence of the lineage (though not individual species) is available from Pinder et al. (2010). No representatives of the lineage have been found to date in Kimberley or south of Perth. One would expect the lineage to occur in Kimberley to bridge the gap between the occurrence of $B$. nimala in the NT and $B$. koendersae sp. nov. and $B$. shieli sp. nov. in the Pilbara, but thus far the only Bennelongia species known from Kimberley is B. kimberleyensis within the B. australis lineage (Martens et al. 2012).

In line with earlier findings in other Bennelongia lineages, most species of the $B$. nimala lineage have restricted distributions, with $B$. nimala being known only from the NT, $B$. koendersae sp. nov. and $B$. shieli sp. nov. being restricted to Pilbara and $B$. pinderi sp. nov. occurring only in the Murchison region. In contrast, Bennelongia muggon sp. nov. is widespread, being recorded from Carnarvon to south of Perth, a distance of $800 \mathrm{~km}$. Bennelongia tirigie sp. nov. appears to be even more widespread, with most records being from north of Carnarvon in the Gascoyne region and an outlying population occurring at Crackers' Swamp about $1000 \mathrm{~km}$ to the south. In addition to this surprising disjunct distribution, there are also ecological differences with northern localities all being turbid water claypans, while Crackers' Swamp is a clear-water body. Nevertheless, the specimens of all localities, including from Crackers' Swamp, cluster tightly together in the COI-tree and have a very similar morphology, so conspecificity cannot be doubted at this stage.

The results for genetic species boundaries of the B. nimala lineage match the morphological species descriptions. With the possible exception of the enigmatic "species 15" from Pilbara, the morphology of which remains unknown, no cryptic species were discovered with molecular methods in this lineage.

\section{B. triangulata sp. nov.}

Bennelongia triangulata sp. nov. is an aberrant species in the genus, as its triangular shape is different from all other congeneric species. The morphology of the latest instar juveniles is even more different, with a ventral side that is completely flattened (De Deckker \& Martens 2013). Nevertheless, marginal valve structures are typical of the genus and the soft parts are very similar to those of other Bennelongia species, albeit slightly more elongated. Accordingly, we have decided to maintain this species within the genus Bennelongia, despite its different habitus.

This species is common in the turbid clay pans of Murchison, Gascoyne and coastal southern Pilbara with a latitudinal range of approximately $550 \mathrm{~km}$. More information on the species range and habitat preferences is available from the collecting records in Halse et al. (2000) and Pinder et al. (2010).

Bennelongia triangulata sp. nov. can occur in highly arched and more elongated forms (see Figs 1112) and both forms have been found in both warmer and colder seasons. In addition, male soft parts (hemipenes, prehensile palps) are similar in both forms. Rpp (Fig. 13D, G) appear to have a different morphology according to valve shape, but intermediate shapes of the distal segment have been found in 
Table 3. Species presently described in Bennelongia, their lineage and their distribution (species in bold are newly described here). Only certain distributions, based on type localities and documented range extensions, are given here. $*$ indicates the type species.

1. *Bennelongia harpago De Deckker \& McKenzie, 1981: QLD

2. Bennelongia tunta De Deckker, 1982: QLD

\section{B. australis lineage}

3. Bennelongia australis (Brady, 1886): SA (uncertain species)

4. Bennelongia bidgelangensis Martens et al., 2012: WA, Gascoyne

5. Bennelongia coondinerensis Martens et al., 2012: WA, Pilbara

6. Bennelongia cuensis Martens et al., 2012: WA, Yilgarn

7. Bennelongia gwelupensis Martens et al., 2012: WA, Perth, southwest coast

8. Bennelongia lata Martens et al., 2012: WA, Gascoyne-Murchinson region

\section{B. barangaroo lineage}

9. Bennelongia barangaroo De Deckker, 1981: WA

10. Bennelongia calei Martens et al., 2013: WA

11. Bennelongia dedeckkeri Shearn et al., 2012: QLD, WA

12. Bennelongia gnamma Martens et al., 2013: WA

13. Bennelongia hirsuta Martens et al., 2013: WA

14. Bennelongia ivanae Martens et al., 2013: WA

15. Bennelongia mckenziei Shearn et al., 2012: QLD

16. Bennelongia mcraeae Martens et al., 2013: WA

17. Bennelongia scanloni Martens et al., 2013: WA

18. Bennelongia timmsi Martens et al., 2013: WA

\section{B. cygnus lineage}

19. Bennelongia cygnus Martens et al., 2012: WA, Swan Valley

20. Bennelongia frumenta Martens et al., 2012: WA, Wheatbelt

\section{B. nimala lineage}

21. Bennelongia koendersae sp. nov.: WA

22. Bennelongia muggon sp. nov.: WA

23. Bennelongia nimala De Deckker, 1981: NT

24. Bennelongia pinderi sp. nov.: WA

25. Bennelongia regina Shearn et al., 2012: QLD

26. Bennelongia shieli $\mathrm{sp}$. nov.: WA

27. Bennelongia tirigie sp. nov.: WA

\section{B. pinpi lineage}

28. Bennelongia kimberleyensis Martens et al., 2012: WA, Kimberley

29. Bennelongia pinpi De Deckker, 1981: QLD

30. Bennelongia strellyensis Martens et al., 2012: WA, Pilbara

\section{B. triangulata lineage}

31. Bennelongia triangulata sp. nov.: WA

some specimens, so that the observed differences may be artefacts of the dissected limb's position on a slide. Unfortunately, only older material of the elongated forms was available so that molecular data cannot be compared for the two morphological forms. From the network in Fig. 3 it can be seen that $B$. triangulata sp. nov. is genetically highly variable, but there are no indications of the existence of cryptic species, as all haplotypes remain connected.

With the six new species described here, the genus Bennelongia now comprises 31 nominal species, divided over at least 7 lineages (Table 3), but several new species still await description. 


\section{Acknowledgments}

The authors gratefully acknowledge the financial support by an ABRS-grant (nr RF211-33: 'Biodiversity and Taxonomy of Ostracoda (Crustacea) from temporary water bodies of inland Western Australia') and of the Edith Cowan University Industry Collaboration grant. KM \& IS acknowledge the Western Australian Department of Parks and Wildlife (2006) and Bennelongia Pty Ltd (2008, 2009, 2010) for financial support during several scientific stays in Perth, as well as the financial contribution of the FWO Vlaanderen (Fund for Scientific Research, Flanders) in the form of travel grants in 2010 (V4.172.10N \& V4.173.10N), and the projects 1.5.172.09 (Krediet aan Navorsers) and G.0118.03N (projectonderzoek). KM and IS also thank the people of Bennelongia Pty Ltd for continuous logistic support (lab space, use of microscopes, etc.) and for unfailing companionship in the lab, and they thank their son Emrys for invaluable help with sorting living specimens in the field as well as in the lab. David Cale, Adrian Pinder (DPaW, Kensington), Andrew Storey (Wetland Research \& Management, Perth), Brian Timms (Newcastle) and Jane McRae (Bennelongia Pty Ltd) are acknowledged for collecting much of the material described in the present paper.

Julien Cilis and Claudine Behen (RBINS, Brussels) provided technical assistance with the SEM micrographs and with the line drawings, respectively. Kristiaan Hoedemakers (RBINS) produced the SEM plates and supervised the entire production of the manuscript. Mike Scanlon (Bennelongia Pty Ltd) produced the map. IS thanks Annette Koenders (Edith Cowan University, Perth) and Mike Johnson (University of Western Australia, Perth) for providing laboratory space for the molecular part of this research. Two anonymous referees are thanked for their valuable comments.

\section{References}

Altschul S.F., Gish W., Miller W., Myers E.W. \& Lipman D.J. 1990. Basic local alignment search tool. Journal of Molecular Biology 215: 403-410. http://dx.doi.org/10.1016/S0022-2836(05)80360-2

Birky C.W. Jr. 2013. Species detection and identification in sexual organisms using population genetic theory and DNA sequences. PLoS ONE 8: e52544. http://dx.doi.org/10.1371/journal.pone.0052544

Birky C.W. Jr. \& Barraclough T.G. 2009. Asexual speciation. In: Schön I., Martens K. \& van Dijk P. (eds) Lost sex: 201-216. Springer Scientific Publishers, Dordrecht.

Birky C.W. Jr., Adams J., Gemmel M. \& Perry J. 2010. Using population genetic theory and DNA sequences for species detection and identification in asexual organisms. PLOS ONE 5: e10609. http:// dx.doi.org/10.1371/journal.pone.0010609

Birky Jr. C.W., Ricci C., Melone G. \& Fontaneto D. 2011. Integrating DNA and morphological taxonomy to describe diversity in poorly studied microscopic animals: new species of the genus Abrochtha Bryce, 1910 (Rotifera: Bdelloidea: Philodinavidae). Zoological Journal of the Linnean Society 161: 723-734. http://dx.doi.org/10.1111/j.1096-3642.2010.00674.x

Bode S.N.S., Lamatsch D.K., Martins M.J.F., Schmit O., Vandekerkhove J., Mezquita F., Namiotko T., Rossetti G., Schön I., Butlin R.K. \& Martens K. 2010. Exceptional cryptic diversity and multiple origins of parthenogenesis in a freshwater ostracod. Molecular Phylogeny and Evolution 54: 542-552. http:// dx.doi.org/10.1016/j.ympev.2009.08.022

Broodbakker N.W. \& Danielopol D.L. 1982. The chaetotaxy of Cypridacea (Crustacea, Ostracoda) limbs: proposals for a descriptive model. Bijdragen tot de Dierkunde 52: 103-120.

Clement M., Posada D. \& Crandall K. 2000. TCS: a computer program to estimate gene genealogies. Molecular Ecology, 9: 1657-1660. http://dx.doi.org/10.1046/j.1365-294x.2000.01020.x 
MARTENS K., HALSE S. \& SCHÖN I., Bennelongia lineages in Western Australia

Darriba D., Taboada G.L., Doallo R. \& Posada D. 2012. jModelTest 2: more models, new heuristics and parallel computing. Nature Methods 9: 772. http://dx.doi.org/10.1038/nmeth.2109

De Deckker P. 1981. Taxonomy and ecological notes of some ostracods from Australian inland waters. Transactions of the Royal Society of South Australia 105: 91-138.

De Deckker P. 1982. On Bennelongia tunta De Deckker sp. nov. A Stereo-Atlas of Ostracod Shells 9: $117-124$.

De Deckker P. \& McKenzie K.G. 1981. Bennelongia, a new cyprididid ostracod genus from Australasia. Transactions of the Royal Society of South Australia 105: 53-58.

De Deckker P. \& Martens K. 2013. Extraordinary morphological changes in valve morphology during the ontogeny of several species of the Australian ostracod genus Bennelongia (Crustacea, Ostracoda). European Journal of Taxonomy 36: 1-37. http://dx.doi.org/10.5852/ejt.2013.36

Folmer O., Black M., Hoeh W., Lutz R. \& Vrijenhoek R. 1994. DNA primers for amplification of mitochondrial cytochrome c oxidase subunit I from diverse metazoan invertebrates. Molecular Marine Biology and Biotechnology 3: 294-299.

Fontaneto D., Herniou E.A., Boschetti C., Caprioli M., Melone G., Ricci C. \& Barraclough T. 2007. Independently evolving species in asexual bdelloid rotifers. PLoS Biology 5: e87. http://dx.doi. org/10.1371/journal.pbio.0050087

Fontaneto D., Kaya M., Herniou E.A. \& Barraclough T.G. 2009. Extreme levels of hidden diversity in microscopic animals (Rotifera) revealed by DNA taxonomy. Molecular Phylogenetics and Evolution 53: 182-189. http://dx.doi.org/10.1016/j.ympev.2009.04.011

Guindon S. \& Gascuel O. 2003. PhyML - a simple, fast, and accurate algorithm to estimate large phylogenies by maximum likelihood. Systematic Biology 52: 696-704. http://dx.doi. org/10.1080/10635150390235520

Hall T. 2007. BioEdit: Biological sequence alignment editor for Win95/98/NT/2K/XP [Online]. Website last modified on 27 June 2007 (accessed on 13 September, 2011). Available at http://www.mbio.ncsu. edu/BioEdit/bioedit.html

Halse S.A., Shiel R.J., Storey A.W., Edward D.H.D., Lansbury I., Cale D.J., \& Harvey M.S. 2000. Aquatic invertebrates and waterbirds of wetlands and rivers of the southern Carnarvon Basin, Western Australia. Records of the Western Australian Museum, Supplement 61: 217-267.

Halse S.A. 2002. Diversity of Ostracoda (Crustacea) in inland waters of Western Australia. Verhandlungen der Internationalen Vereinigung für theoretische und angewandte Limnologie 28: 914-918.

Horne D.J., Cohen A. \& Martens K. 2002. Taxonomy, morphology and biology of Quaternary and living Ostracoda. In: Holmes J.A. \& Chivas A.R. (eds) The Ostracoda: Application in Quaternary Research. Geophysical Monograph 131: 5-36. American Geophysical Union, Washington, DC.

Larkin M.A., Blackshields G., Brown N.P., Chenna R., McGettigan P.A., McWilliam H., Valentin F., Wallace I.M., Wilm A., Lopez R., Thompson J.D., Gibson T.J. \& Higgins D.G. 2007. Clustal W and Clustal X version 2.0. Bioinformatics 23: 2947-2948. http://dx.doi.org/10.1093/bioinformatics/btm404

Martens K. 1987. Homology and functional morphology of the sexual dimorphism in the antenna of Sclerocypris Sars, 1924 (Crustacea, Ostracoda, Megalocypridinae). Bijdragen tot de Dierkunde 57: 183-190.

Martens K., Rossetti G. \& De Deckker P. 2004. On a new terrestrial genus and species of Scottiinae (Crustacea, Ostracoda) from Australia, with a discussion on the phylogeny and the zoogeography of the subfamily. Zoologischer Anzeiger 243: 21-36. http://dx.doi.org/10.1016/j.jcz.2004.05.001 
Martens K., Halse S. \& Schön I. 2012. Nine new species of Bennelongia De Deckker \& McKenzie, 1981 (Crustacea, Ostracoda) from Western Australia, with the description of a new subfamily. European Journal of Taxonomy 8: 1-56. http://dx.doi.org/10.5852/ejt.2012.8

Martens K., Halse S.A. \& Schön I. 2013. On the Bennelongia barangaroo lineage (Crustacea, Ostracoda) in Western Australia, with the description of seven new species. European Journal of Taxonomy 66: 1-59. http://dx.doi.org/10.5852/ejt.2013.66

Pinder A.M., Halse S.A., Shiel R.J., \& McRae J.M. 2010. An arid zone awash with diversity: patterns in the distribution of aquatic invertebrates in the Pilbara region of Western Australia. Records of the Western Australia Museum, Supplement 78: 205-246.

Ronquist F., Teslenko M., van der Mark P., Ayres D., Darling A., Hohna S., Larget B., Liu L., Suchard M.A. \& Huelsenbeck J.P. 2011. MrBayes 3.2: Efficient Bayesian phylogenetic inference and model choice across a large model space. Systematic Biology 61: 539-542. http://dx.doi.org/10.1093/sysbio/ sys029

Schön I., Pinto R.L., Halse S.A., Smith A.J., Martens K. \& Birky C.W. Jr. 2012. Cryptic species in putative ancient asexual darwinulids (Crustacea, Ostracoda). PLOS One 7: e39844. http://dx.doi.org/10.1371/journal.pone.0039844

Shearn R., Koenders A., Halse S., Schön I. \& Martens K. 2012. A review of Bennelongia De Deckker \& McKenzie, 1981 (Crustacea, Ostracoda) species from eastern Australia, with the description of three new species. European Journal of Taxonomy 25: 1-35. http://dx.doi.org/10.5852/ejt.2012.25

Tamura K., Stecher G., Peterson D., Filipski A. \& Kumar A. 2013. MEGA6: Molecular Evolutionary Genetics Analysis version 6.0. Molecular Biology and Evolution 30: 2725-2729. http://dx.doi. org $/ 10.1093 / \mathrm{molbev} / \mathrm{mst} 197$

Tsukagoshi A. 1988. Reproductive character displacement in the ostracod genus Cythere. Journal of Crustacean Biology 8: 563-575. http://dx.doi.org/10.2307/1548693

Manuscript received: 21 July 2014

Manuscript accepted: 27 October 2014

Published on: 3 February 2015

Topic editor: Rudy Jocqué

Desk editor: Kristiaan Hoedemakers

Printed versions of all papers are also deposited in the libraries of the institutes that are members of the EJT consortium: Muséum National d'Histoire Naturelle, Paris, France; Botanic Garden Meise, Belgium; Royal Museum for Central Africa, Tervuren, Belgium; Natural History Museum, London, United Kingdom; Royal Belgian Institute of Natural Sciences, Brussels, Belgium; Natural History Museum of Denmark, Copenhagen, Denmark. 